\title{
One-pot Synthesis of Substituted 2-Aminobenzo[b]thiophenes.
}

\author{
Andrey Y. Solovyev, Dmitry A. Androsov and Douglas C. Neckers* \\ Center for Photochemical Sciences, Bowling Green State University, \\ Bowling Green, Ohio 43403, USA \\ neckers@photo.bgsu.edu
}

List of contents

Page number

${ }^{1} \mathrm{H}$-spectrum of methyl-(5-nitro-benzo[b]thiophen-2-yl)-amine (3a) in $\mathrm{CDCl}_{3}$. S3

${ }^{13} \mathrm{C}$-spectrum of methyl-(5-nitro-benzo[b]thiophen-2-yl)-amine (3a) in $\mathrm{CDCl}_{3}$. S4

MS of methyl-(5-nitro-benzo[b]thiophen-2-yl)-amine (3a). S5

${ }^{1} \mathrm{H}$-spectrum of allyl-(5-nitro-benzo[b]thiophen-2-yl)-amine (3b) in $\mathrm{CDCl}_{3}$. $\quad$ S6

${ }^{13}$ C-spectrum of allyl-(5-nitro-benzo[b]thiophen-2-yl)-amine (3b) in $\mathrm{CDCl}_{3}$.

MS of allyl-(5-nitro-benzo[b]thiophen-2-yl)-amine (3b). $\quad$ S8

${ }^{1} \mathrm{H}$-spectrum of butyl-(5-nitro-benzo[b]thiophen-2-yl)-amine (3c) in $\mathrm{CDCl}_{3}$. $\quad$ s9

${ }^{13}$ C-spectrum of butyl-(5-nitro-benzo[b]thiophen-2-yl)-amine (3c) in $\mathrm{CDCl}_{3}$. $\quad \mathbf{S 1 0}$

MS of butyl-(5-nitro-benzo[b]thiophen-2-yl)-amine (3c). $\quad$ S11

${ }^{1} \mathrm{H}$-spectrum of benzyl-(5-nitro-benzo[b]thiophen-2-yl)-amine (3d) in $\mathrm{CDCl}_{3}$. $\mathbf{S 1 2}$

${ }^{13}$ C-spectrum of benzyl-(5-nitro-benzo[b]thiophen-2-yl)-amine (3d) in $\mathrm{CDCl}_{3}$. $\mathbf{S 1 3}$

MS of benzyl-(5-nitro-benzo[b]thiophen-2-yl)-amine (3d). $\quad$ S14

${ }^{1} \mathrm{H}$-spectrum of isopropyl-(5-nitro-benzo[b]thiophen-2-yl)-amine (3e) in $\mathrm{CDCl}_{3}$. $\quad \mathbf{S 1 5}$

${ }^{13} \mathrm{C}$-spectrum of isopropyl-(5-nitro-benzo[b]thiophen-2-yl)-amine (3e) in $\mathbf{S 1 6}$ $\mathrm{CDCl}_{3}$. 
MS of isopropyl-(5-nitro-benzo[b]thiophen-2-yl)-amine (3e).

${ }^{1} \mathrm{H}$-spectrum of cyclopentyl-(5-nitro-benzo[b]thiophen-2-yl)-amine (3f) in S18 $\mathrm{CDCl}_{3}$.

${ }^{13} \mathrm{C}$-spectrum of cyclopentyl-(5-nitro-benzo[b]thiophen-2-yl)-amine (3f) in

S19 $\mathrm{CDCl}_{3}$.

MS of cyclopentyl-(5-nitro-benzo[b]thiophen-2-yl)-amine (3f).

S20

${ }^{1} \mathrm{H}$-spectrum of cyclohexyl-(5-nitro-benzo[b]thiophen-2-yl)-amine (3g) in

S21 $\mathrm{CDCl}_{3}$.

${ }^{13} \mathrm{C}$-spectrum of cyclohexyl-(5-nitro-benzo[b]thiophen-2-yl)-amine (3g) in

S22 $\mathrm{CDCl}_{3}$.

MS of cyclohexyl-(5-nitro-benzo[b]thiophen-2-yl)-amine (3g).

S23

${ }^{1} \mathrm{H}$-spectrum of dimethyl-(5-nitro-benzo[b]thiophen-2-yl)-amine (3h) in $\mathrm{CDCl}_{3}$.

S24

${ }^{13} \mathrm{C}$-spectrum of dimethyl-(5-nitro-benzo[b]thiophen-2-yl)-amine (3h) in

S25 $\mathrm{CDCl}_{3}$.

MS of dimethyl-(5-nitro-benzo[b]thiophen-2-yl)-amine (3h).

S26

${ }^{1} \mathrm{H}$-spectrum of 1-(5-nitro-benzo[b]thiophen-2-yl)-pyrrolidine (3i) in $\mathrm{CDCl}_{3}$. $\quad$ S27

${ }^{13} \mathrm{C}$-spectrum of 1-(5-nitro-benzo[b]thiophen-2-yl)-pyrrolidine (3i) in $\mathrm{CDCl}_{3}$.

MS of 1-(5-nitro-benzo[b]thiophen-2-yl)-pyrrolidine (3i). $\quad$ S29

${ }^{1} \mathrm{H}$-spectrum of 1-(5-nitro-benzo[b]thiophen-2-yl)-piperidine (3j) in $\mathrm{CDCl}_{3}$. $\quad$ S30

${ }^{13}$ C-spectrum of 1-(5-nitro-benzo[b]thiophen-2-yl)-piperidine (3j) in $\mathrm{CDCl}_{3}$. $\quad \mathbf{S 3 1}$

MS of 1-(5-nitro-benzo[b]thiophen-2-yl)-piperidine (3j). $\quad$ S32

${ }^{1} \mathrm{H}$-spectrum of 4-(5-nitro-benzo[b]thiophen-2-yl)-morpholine (3k) in $\mathrm{CDCl}_{3}$. $\quad$ S33

${ }^{13}$ C-spectrum of 4-(5-nitro-benzo[b]thiophen-2-yl)-morpholine (3k) in $\mathrm{CDCl}_{3}$. $\quad \mathbf{S 3 4}$

MS of 4-(5-nitro-benzo[b]thiophen-2-yl)-morpholine (3k). $\quad$ S35

${ }^{1} \mathrm{H}$-spectrum of 3-methyl-5-nitro-benzo[ $[d]$ isothiazole (4) in $\mathrm{CDCl}_{3}$. $\quad$ S36

${ }^{13}$ C-spectrum of 3-methyl-5-nitro-benzo $[d]$ isothiazole (4) in $\mathrm{CDCl}_{3}$.

MS of 3-methyl-5-nitro-benzo[d]isothiazole (4). $\quad$ S38

General methods and materials. 


\section{${ }^{1} \mathrm{H}$-spectrum of methyl-(5-nitro-benzo[b]thiophen-2-yl)-amine (3a) in $\mathrm{CDCl}_{3}$.}

2-Methylamino-5-nitrobenzo [b] thiophene AS34_2 Fractions 3-7

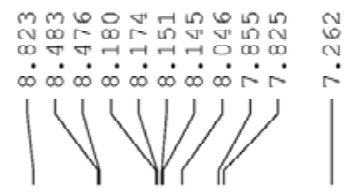

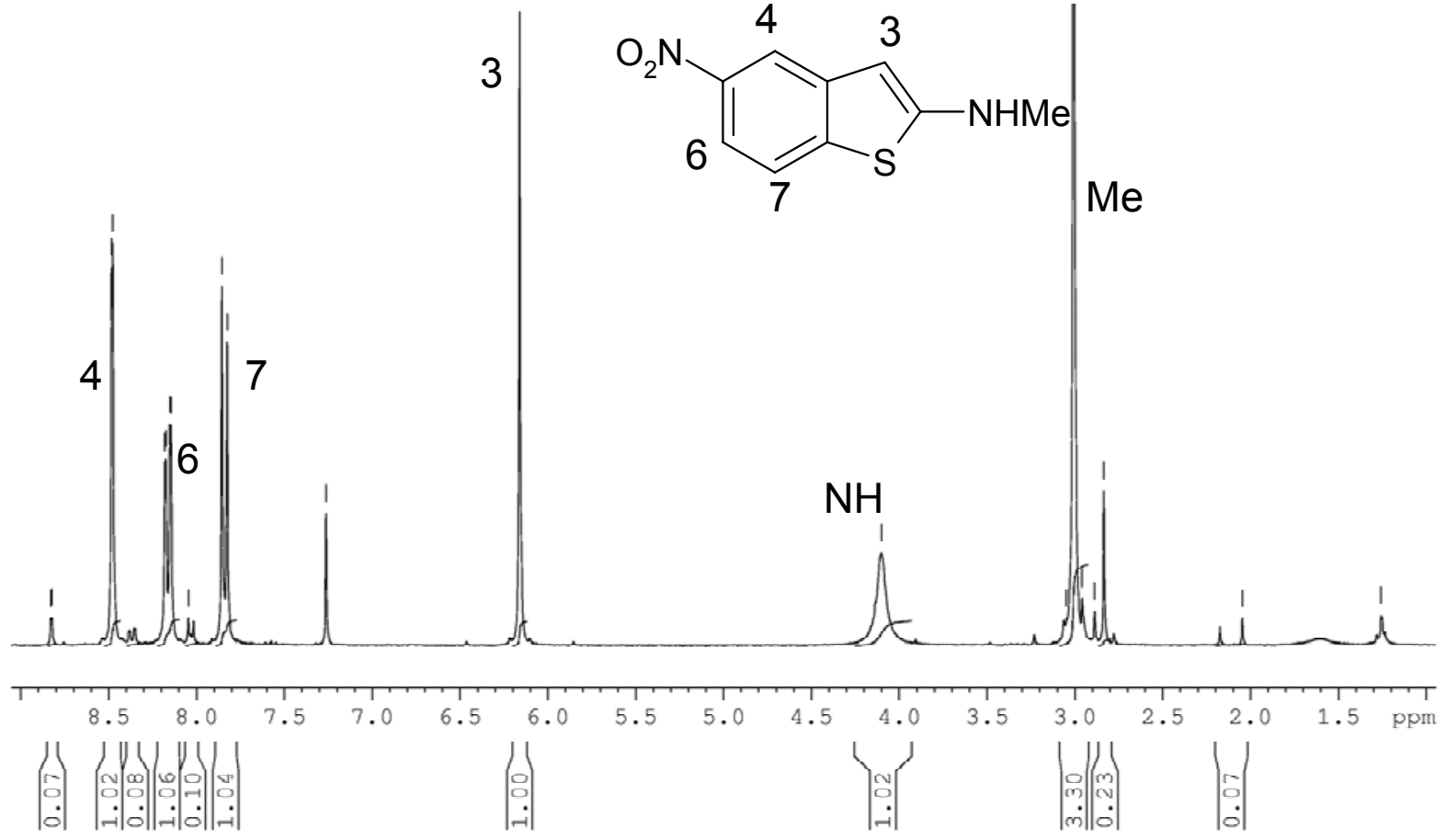

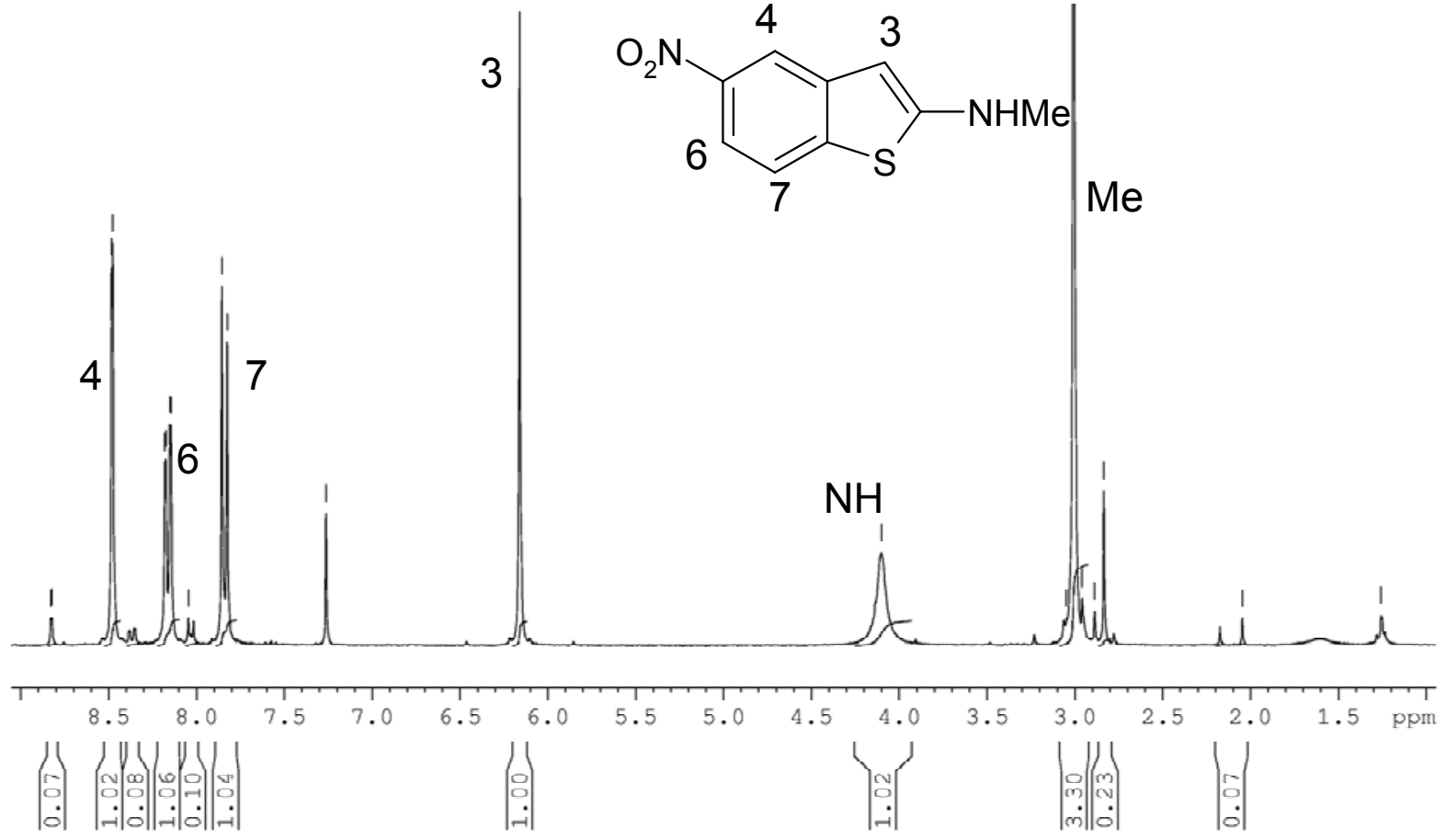

\section{${ }^{1} \mathrm{H} \mathrm{NMR}\left(\mathrm{CDCl}_{3}\right)$}


${ }^{13} \mathrm{C}$-spectrum of methyl-(5-nitro-benzo[b]thiophen-2-yl)-amine (3a) in $\mathrm{CDCl}_{3}$.

\section{${ }^{13} \mathrm{C} \mathrm{NMR}\left(\mathrm{CDCl}_{3}\right)$}

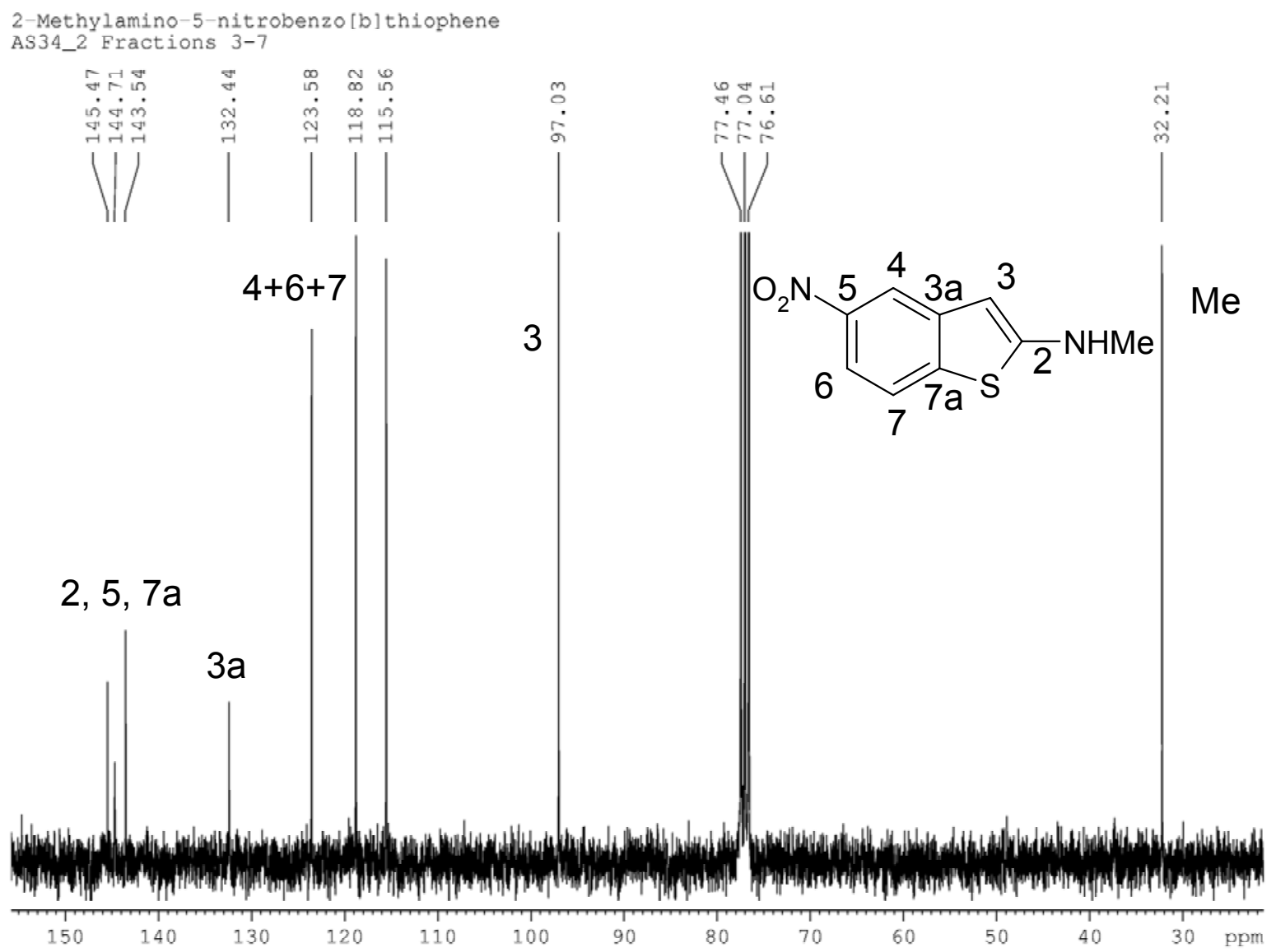




\section{MS of methyl-(5-nitro-benzo[b]thiophen-2-yl)-amine (3a)}

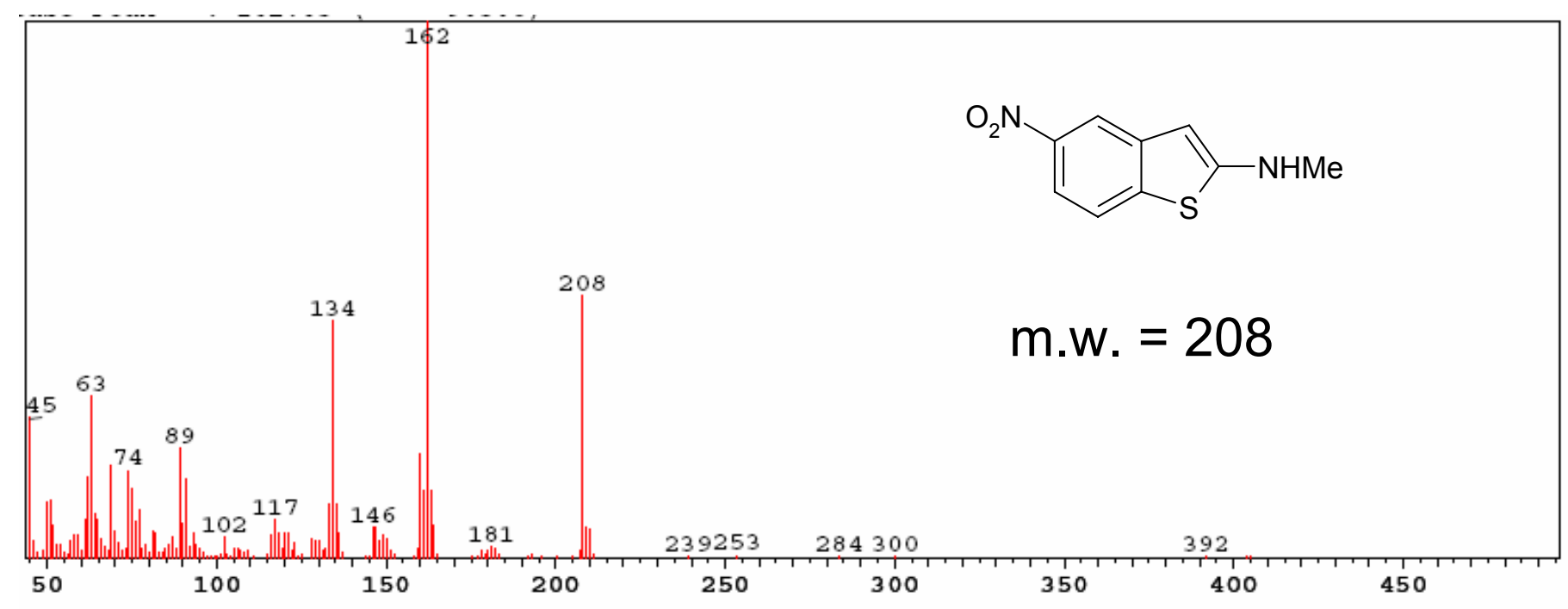




\section{${ }^{1} \mathrm{H}$-spectrum of allyl-(5-nitro-benzo[b]thiophen-2-yl)-amine (3b) in $\mathrm{CDCl}_{3}$.}

\section{${ }^{1} \mathrm{H} \operatorname{NMR}\left(\mathrm{CDCl}_{3}\right)$}

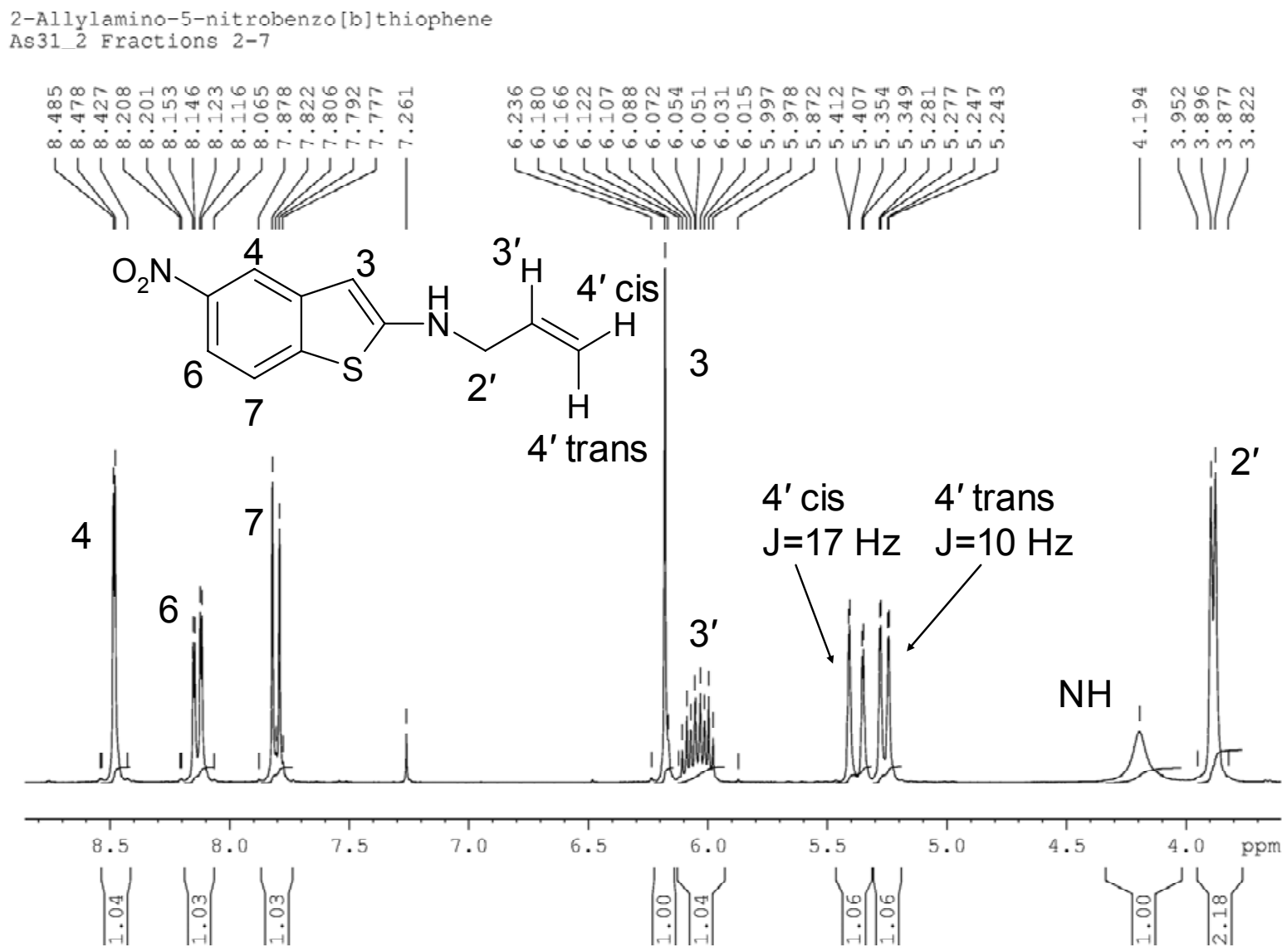




\section{${ }^{13} \mathrm{C}$-spectrum of allyl-(5-nitro-benzo[b]thiophen-2-yl)-amine (3b) in $\mathrm{CDCl}_{3}$.}

\section{${ }^{13} \mathrm{C}$ NMR $\left(\mathrm{CDCl}_{3}\right)$}

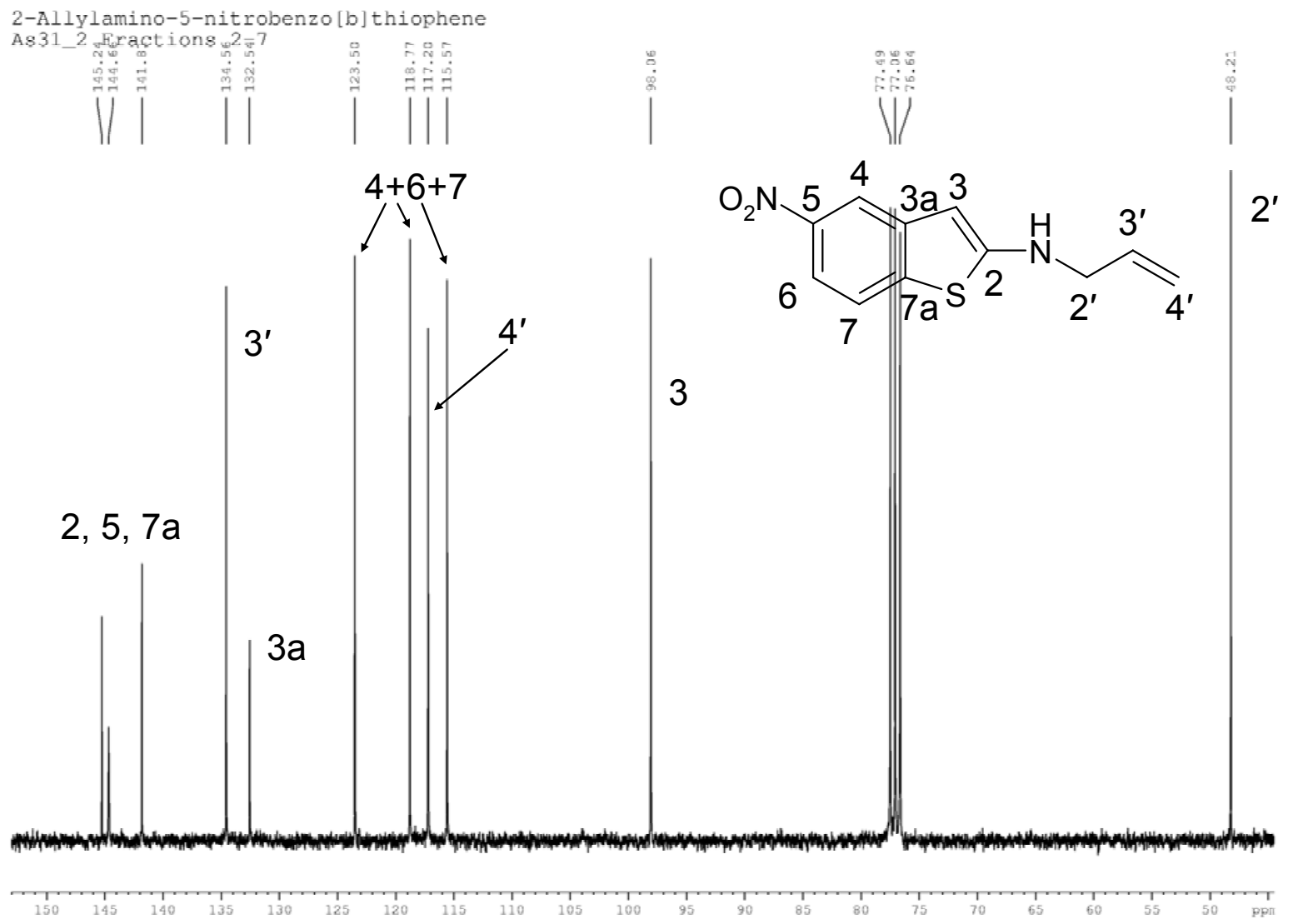


MS of allyl-(5-nitro-benzo[b]thiophen-2-yl)-amine (3b).

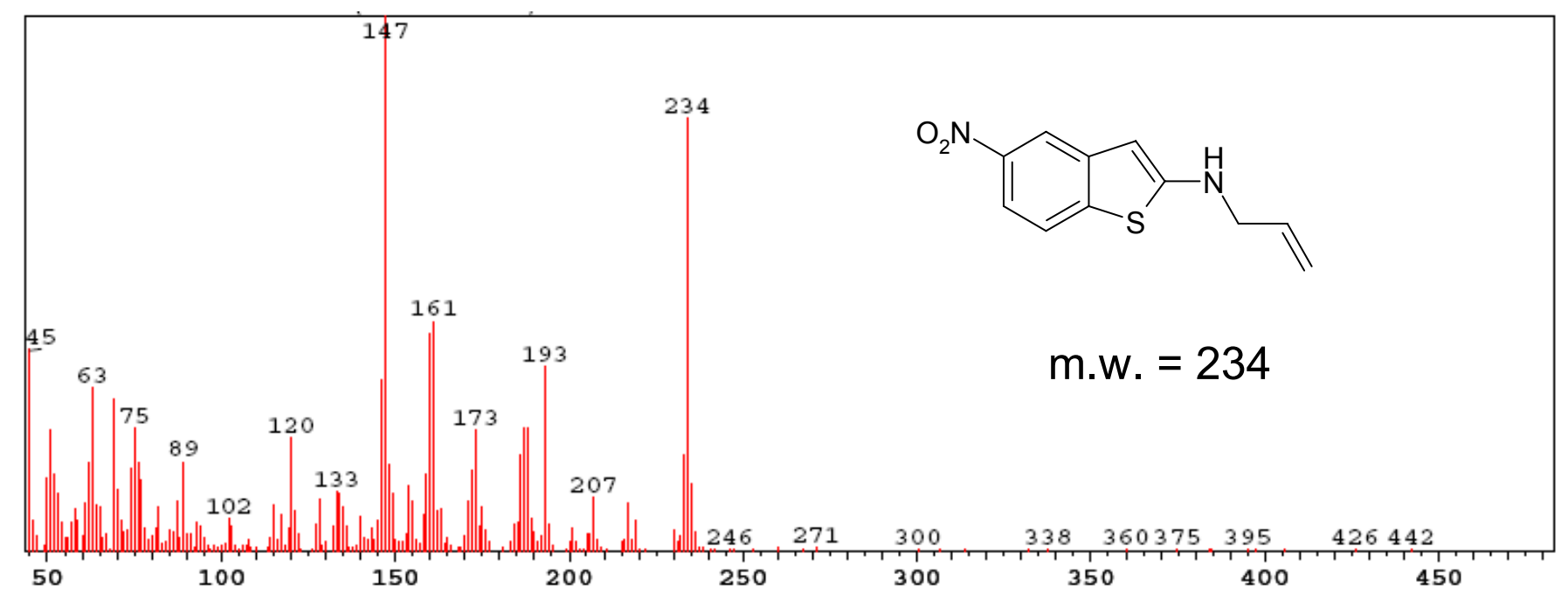




\section{${ }^{1} \mathrm{H}$-spectrum of butyl-(5-nitro-benzo[b]thiophen-2-yl)-amine (3c) in $\mathrm{CDCl}_{3}$.}

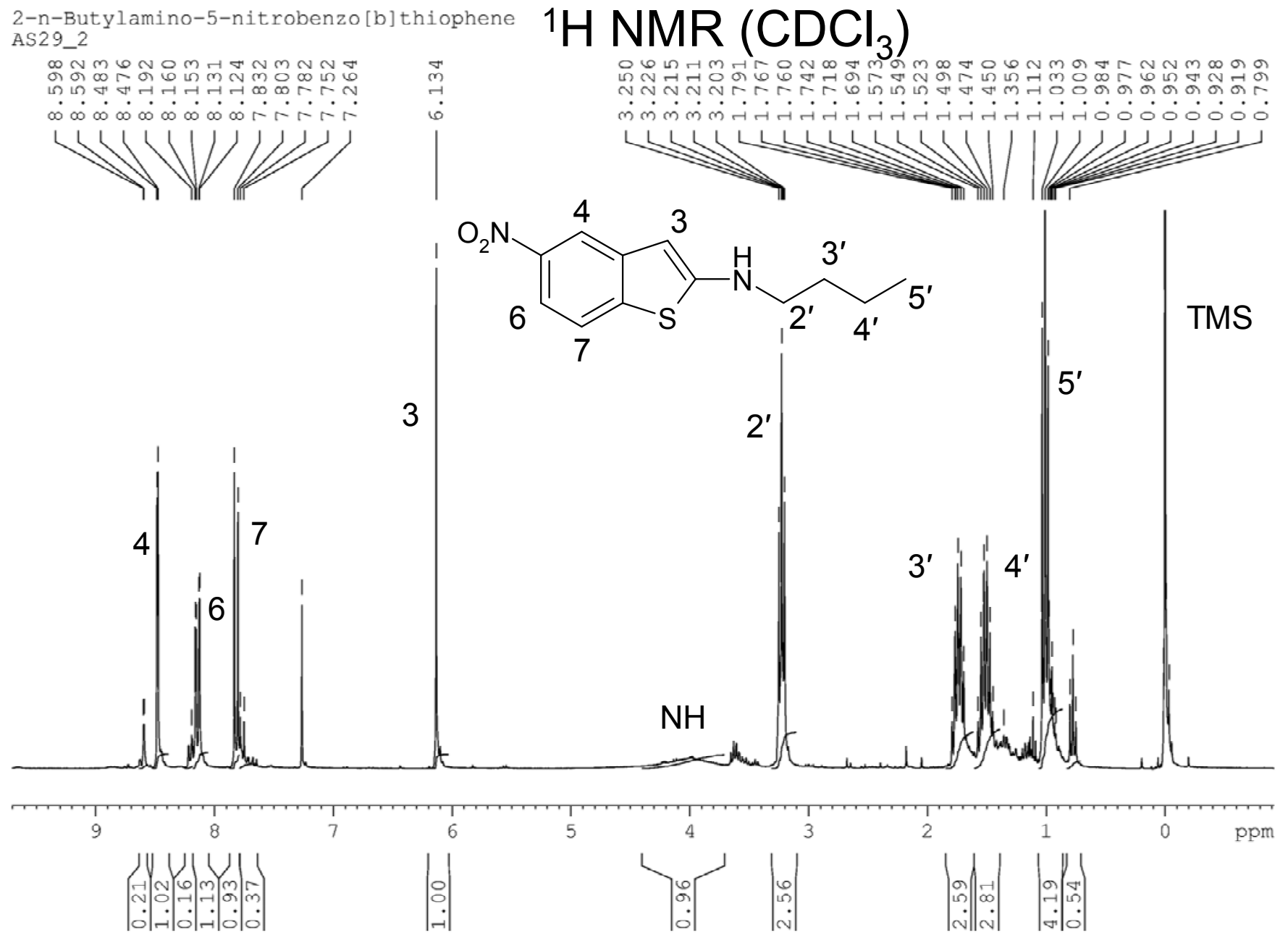




\section{${ }^{13} \mathrm{C}$-spectrum of butyl-(5-nitro-benzo[b]thiophen-2-yl)-amine (3c) in $\mathrm{CDCl}_{3}$.}

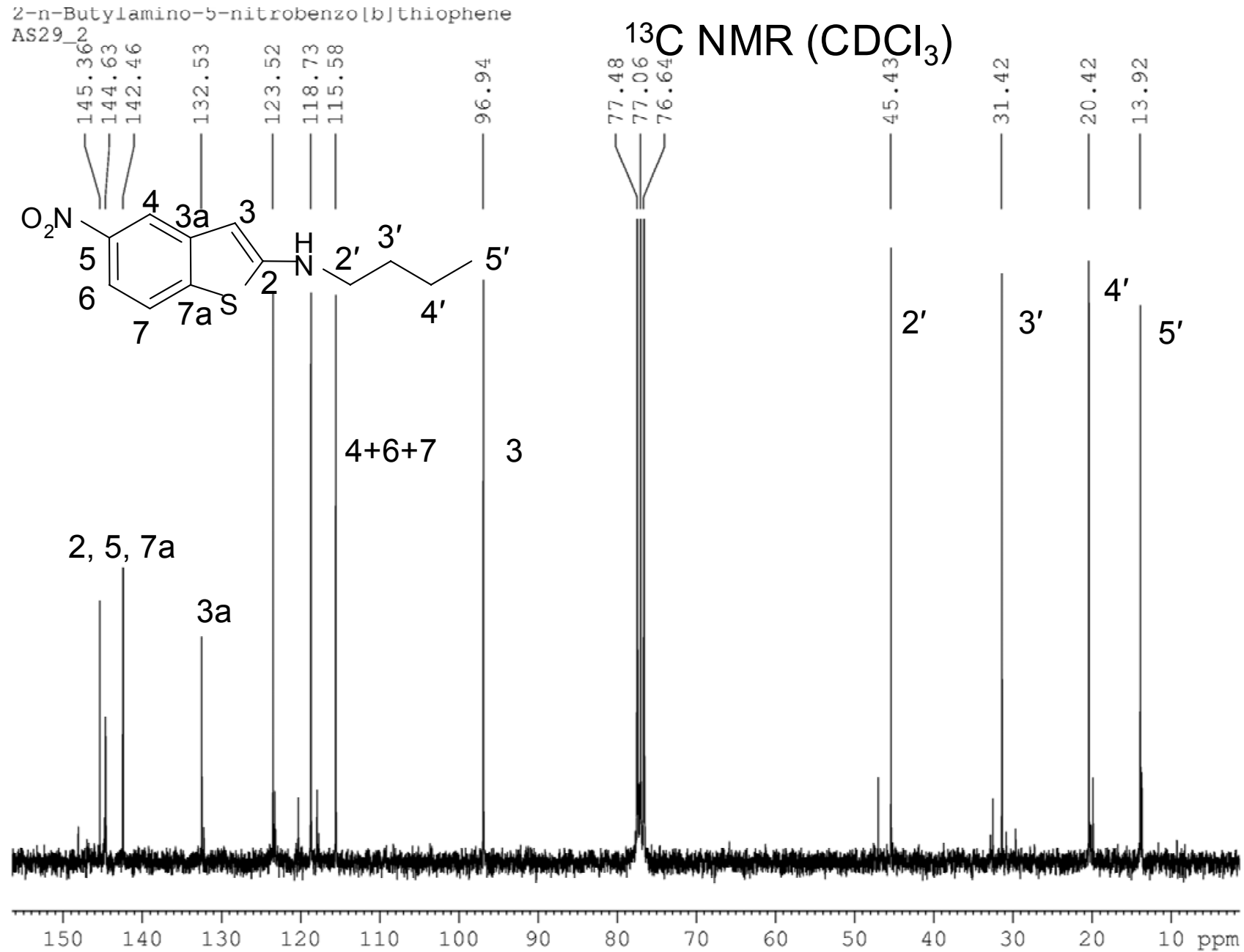




\section{MS of butyl-(5-nitro-benzo[b]thiophen-2-yl)-amine (3c).}

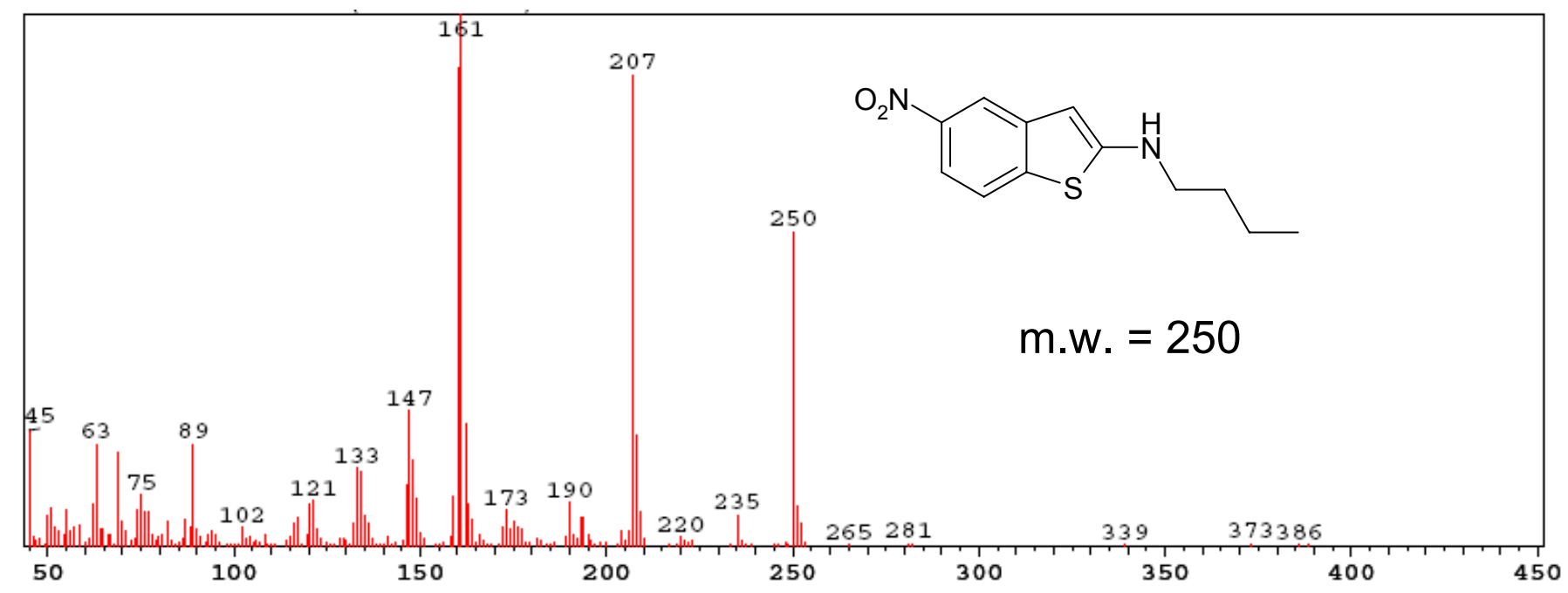


${ }^{1} \mathrm{H}$-spectrum of benzyl-(5-nitro-benzo[b]thiophen-2-yl)-amine (3d) in $\mathrm{CDCl}_{3}$.

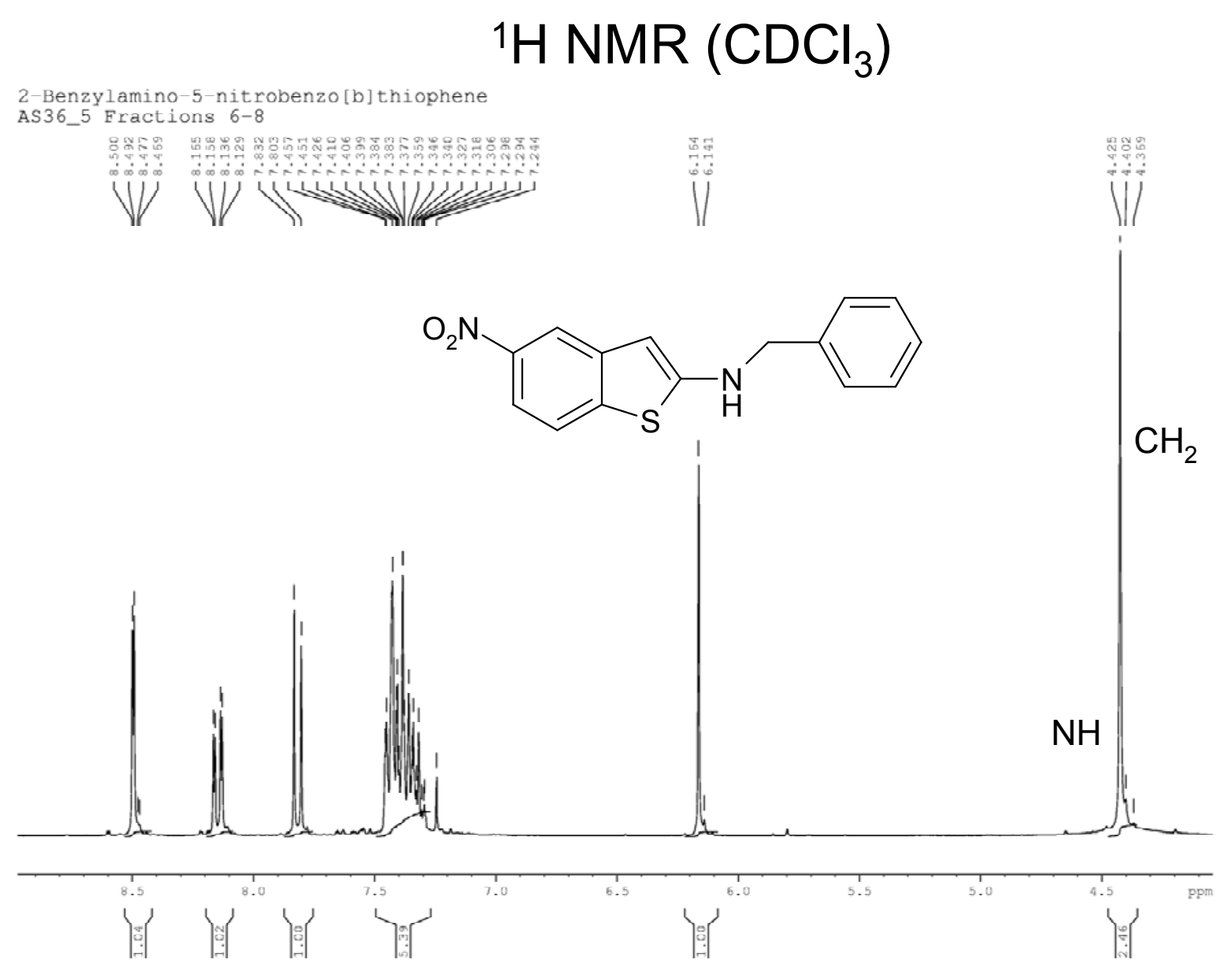


${ }^{13} \mathrm{C}$-spectrum of benzyl-(5-nitro-benzo[b]thiophen-2-yl)-amine (3d) in $\mathrm{CDCl}_{3}$.

\section{${ }^{13} \mathrm{C}$ NMR $\left(\mathrm{CDCl}_{3}\right)$}

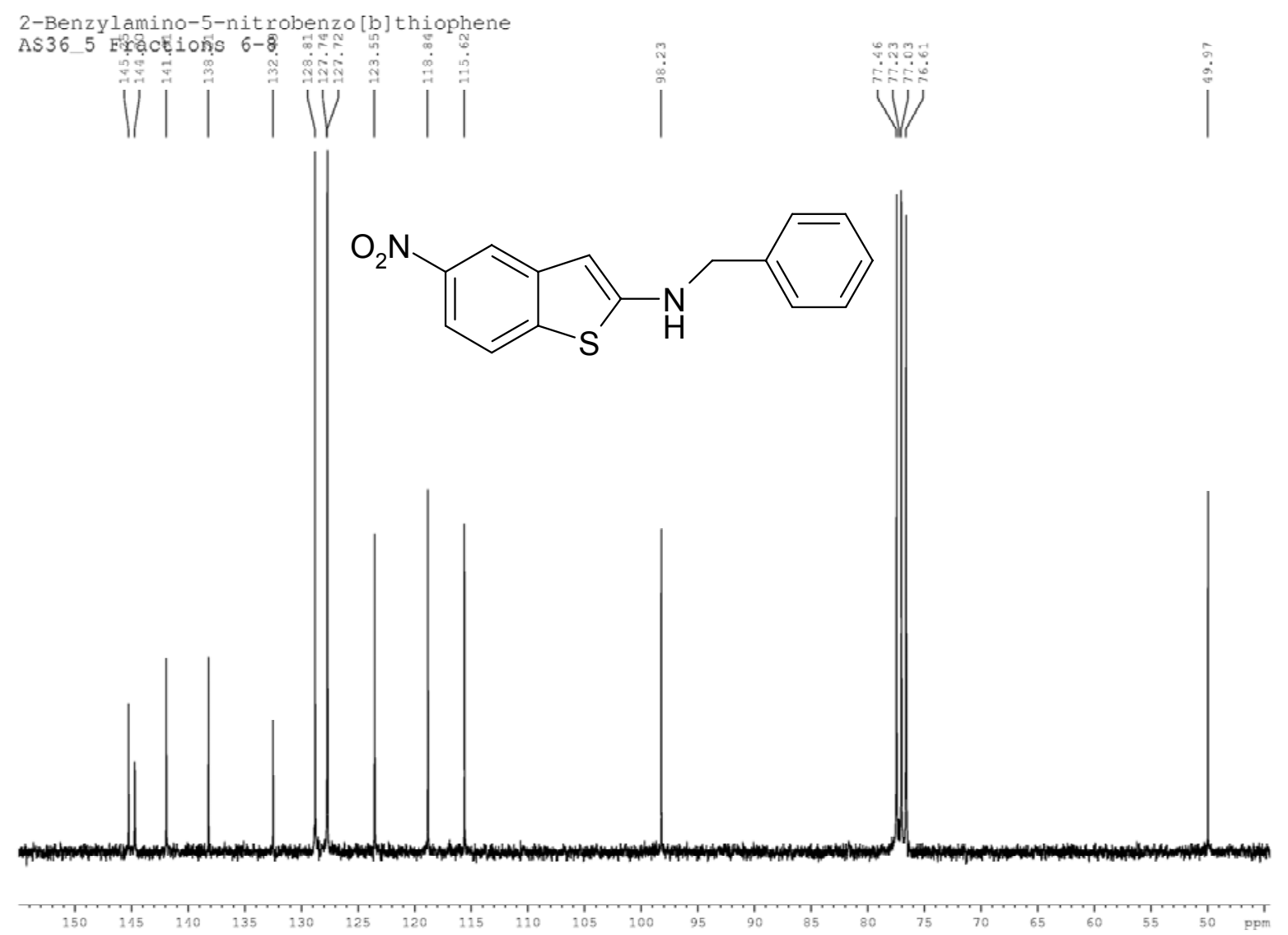


MS of benzyl-(5-nitro-benzo[b]thiophen-2-yl)-amine (3d).

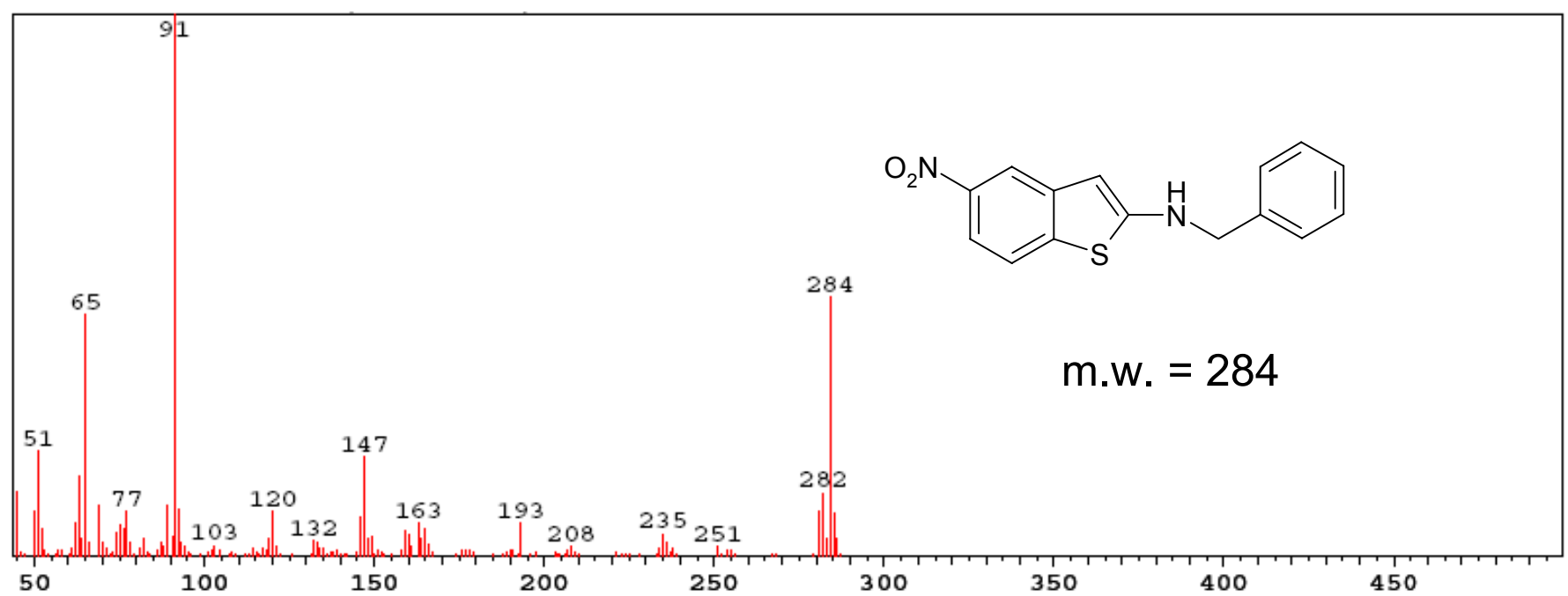




\section{${ }^{1} \mathrm{H}$-spectrum of isopropyl-(5-nitro-benzo[b]thiophen-2-yl)-amine (3e) in $\mathrm{CDCl}_{3}$}

\section{${ }^{1} \mathrm{H} \operatorname{NMR}\left(\mathrm{CDCl}_{3}\right)$}

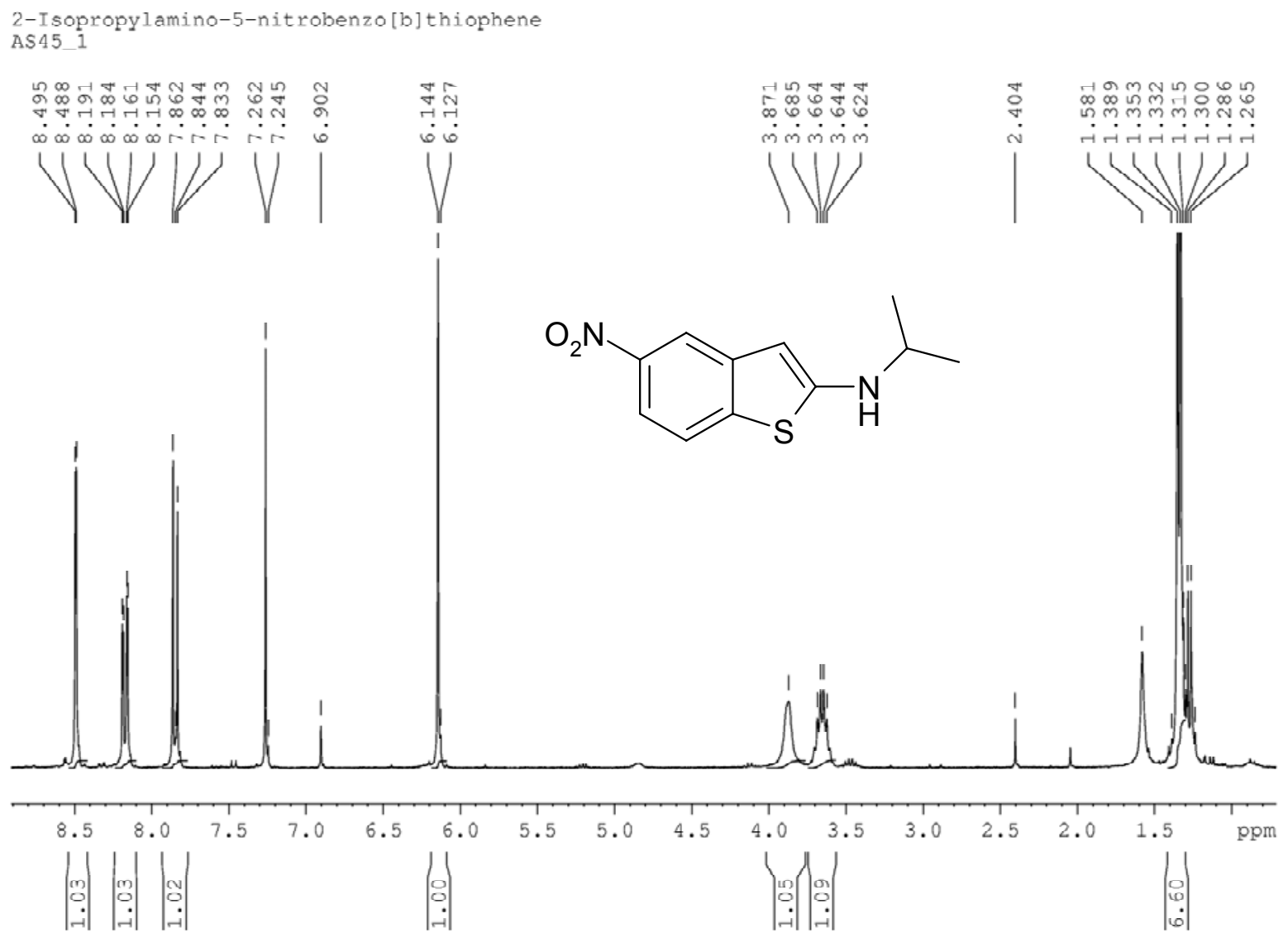




\section{${ }^{13} \mathrm{C}$-spectrum of isopropyl-(5-nitro-benzo[b]thiophen-2-yl)-amine (3e) in $\mathrm{CDCl}_{3}$}

\section{${ }^{13} \mathrm{C} \mathrm{NMR}\left(\mathrm{CDCl}_{3}\right)$}

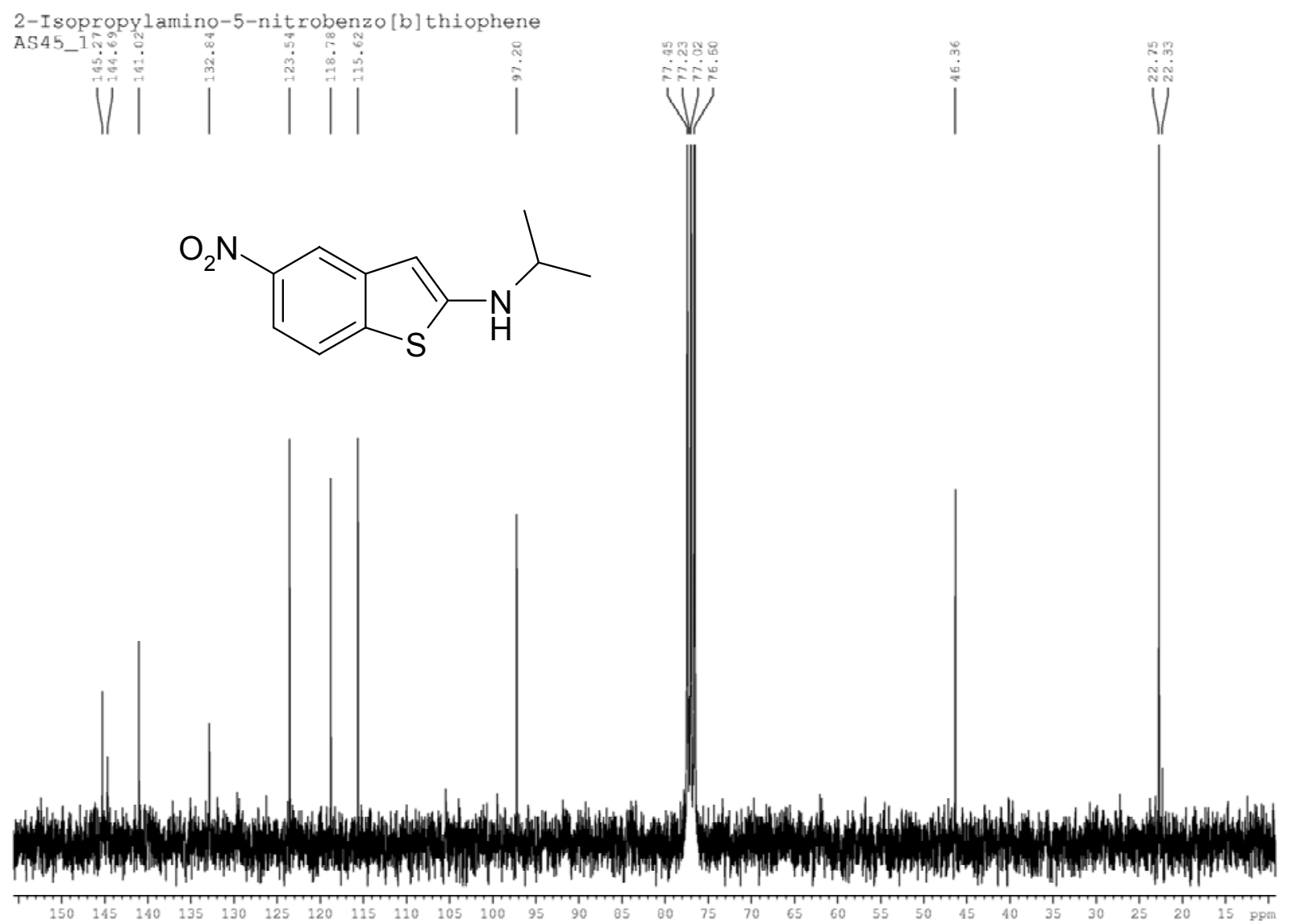


MS of isopropyl-(5-nitro-benzo[b]thiophen-2-yl)-amine (3e).

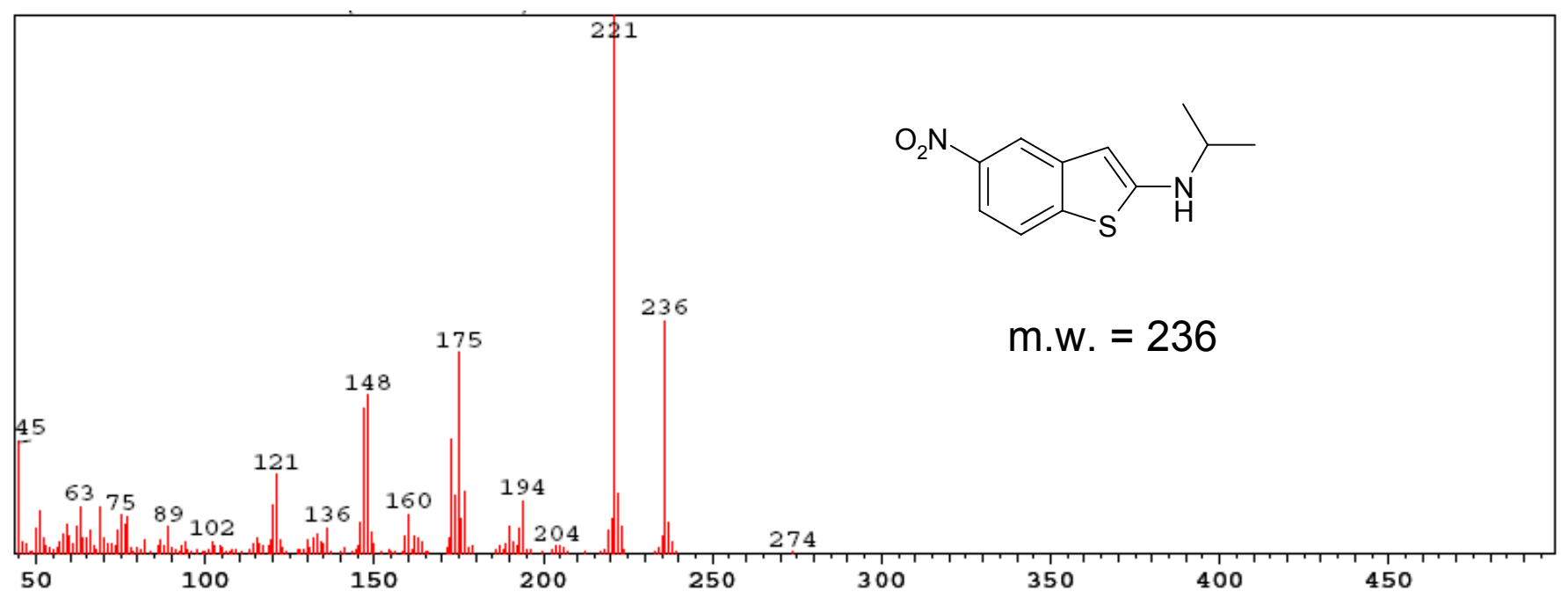




\section{${ }^{1} \mathrm{H}$-spectrum of cyclopentyl-(5-nitro-benzo[b]thiophen-2-yl)-amine (3f) in $\mathrm{CDCl}_{3}$}

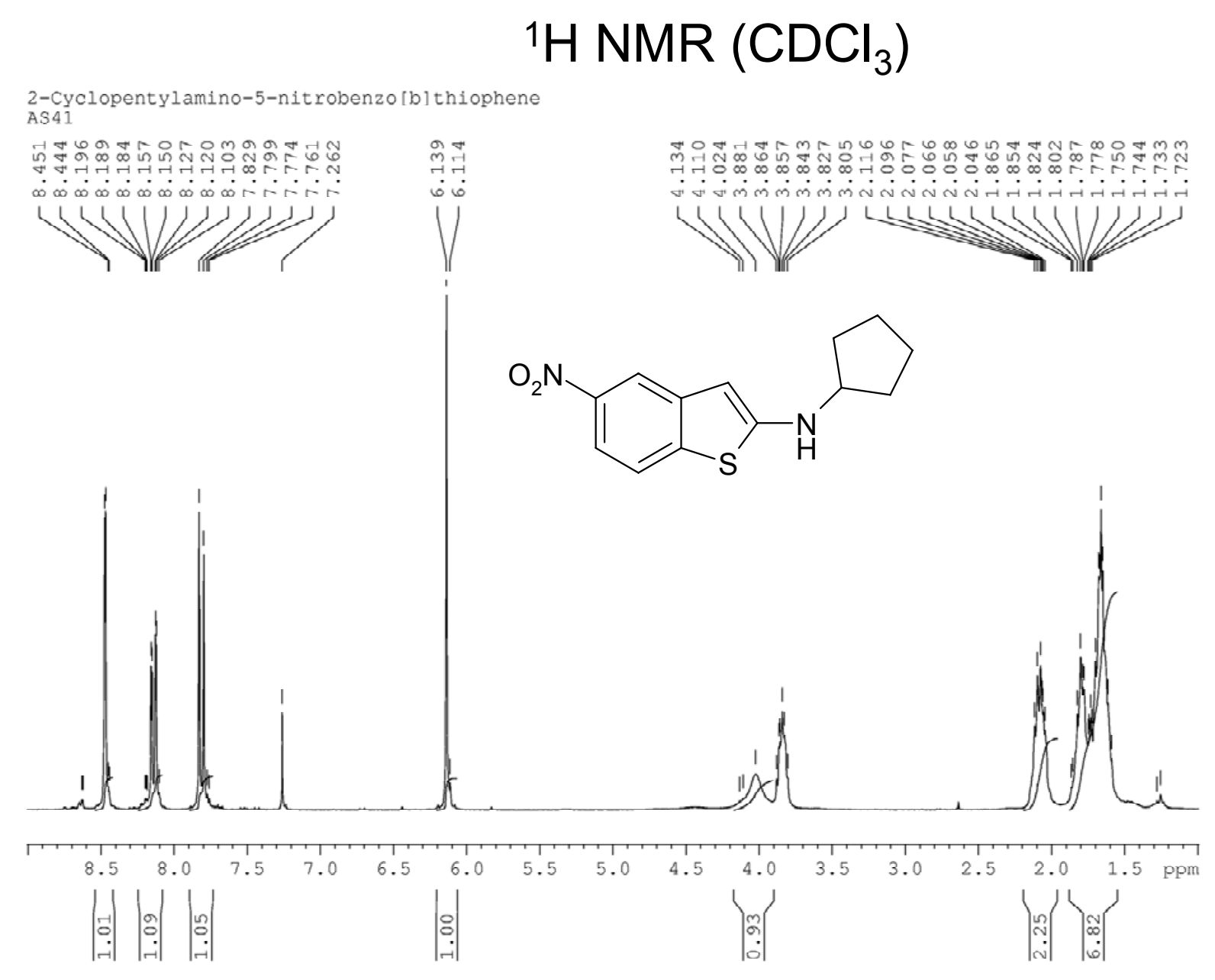




\section{${ }^{13} \mathrm{C}$-spectrum of cyclopentyl-(5-nitro-benzo[b]thiophen-2-yl)-amine (3f) in $\mathrm{CDCl}_{3}$.}

\section{${ }^{13} \mathrm{C} \mathrm{NMR}\left(\mathrm{CDCl}_{3}\right)$}

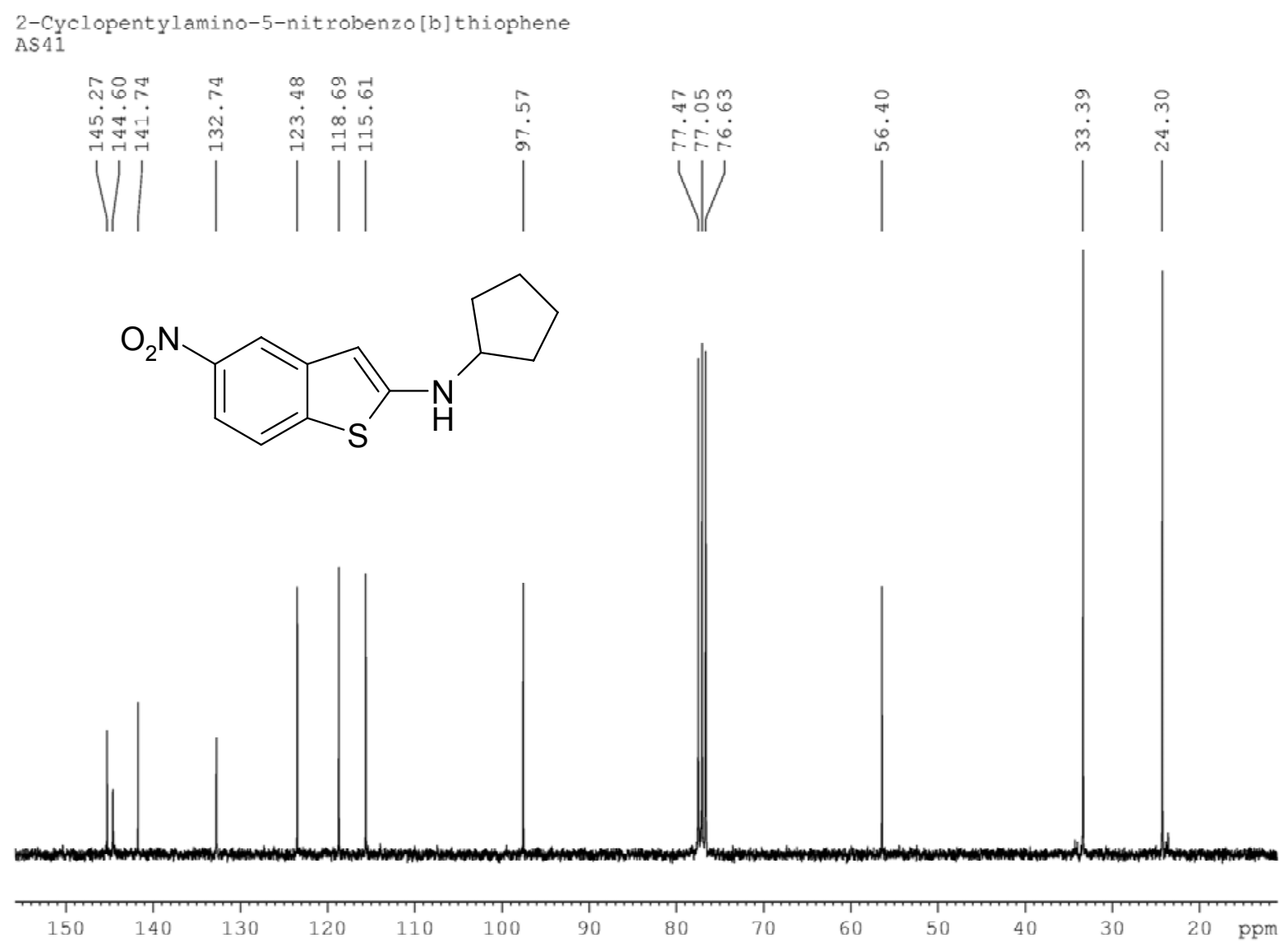


MS of cyclopentyl-(5-nitro-benzo[b]thiophen-2-yl)-amine (3f).

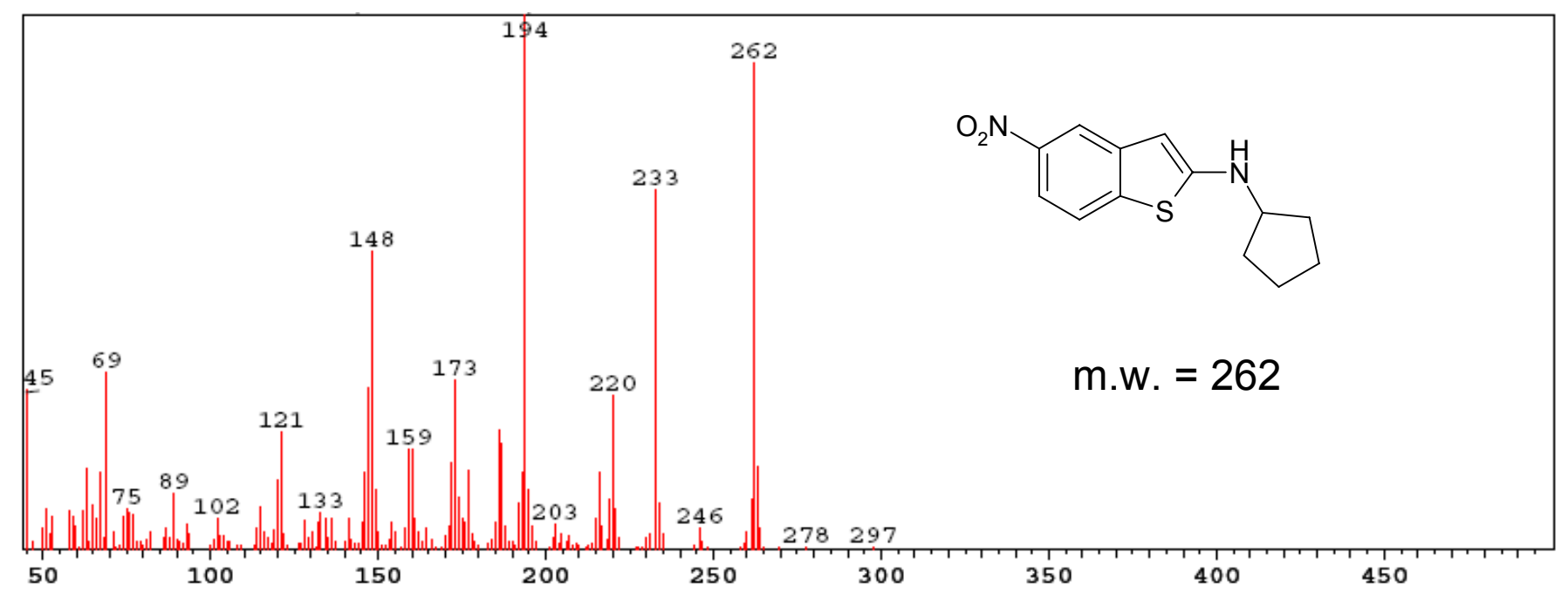




\section{${ }^{1} \mathrm{H}$-spectrum of cyclohexyl-(5-nitro-benzo[b]thiophen-2-yl)-amine (3g) in $\mathrm{CDCl}_{3}$.}

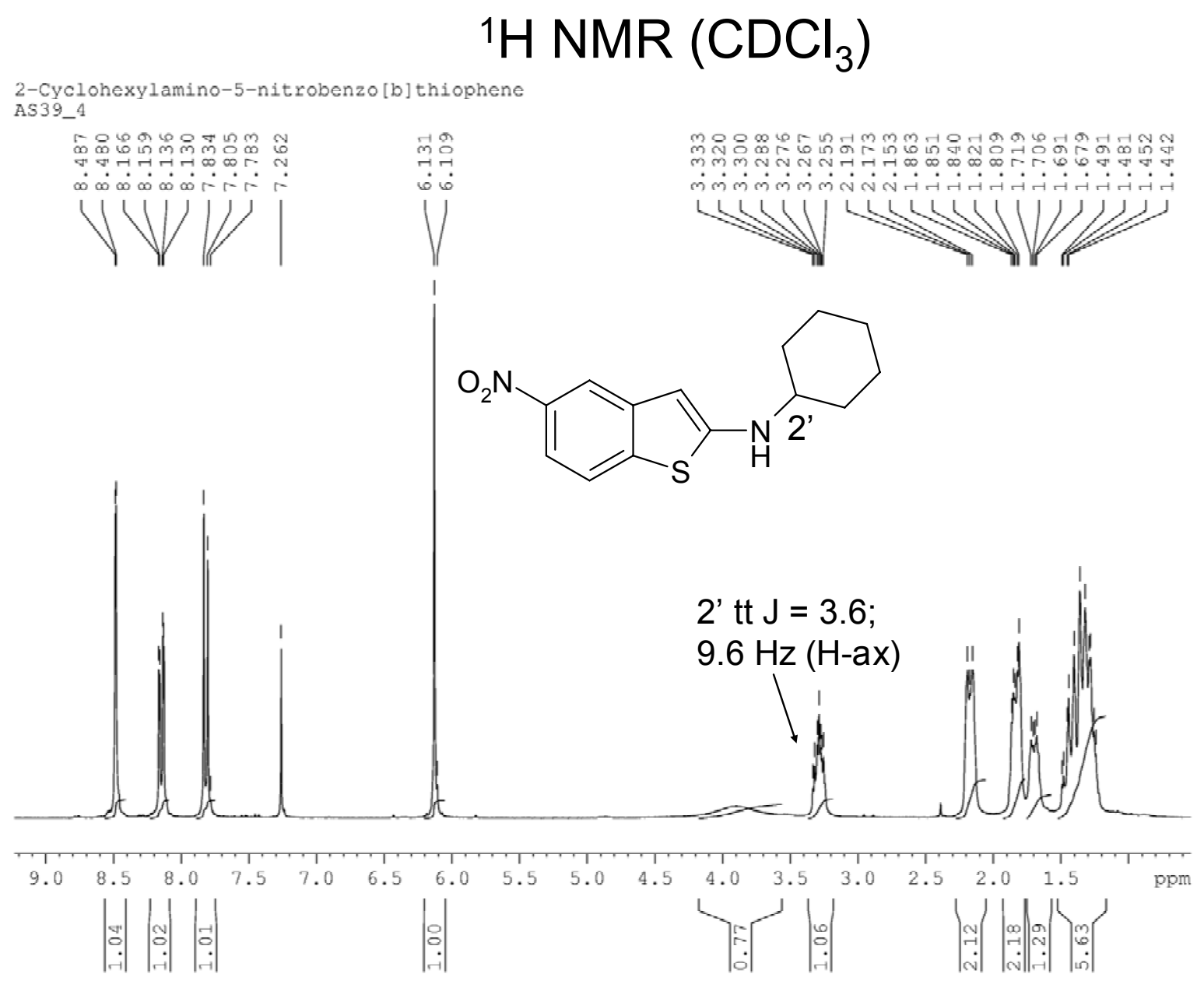


${ }^{13} \mathrm{C}$-spectrum of cyclohexyl-(5-nitro-benzo[b]thiophen-2-yl)-amine (3g) in $\mathrm{CDCl}_{3}$.

\section{${ }^{13} \mathrm{C}$ NMR $\left(\mathrm{CDCl}_{3}\right)$}

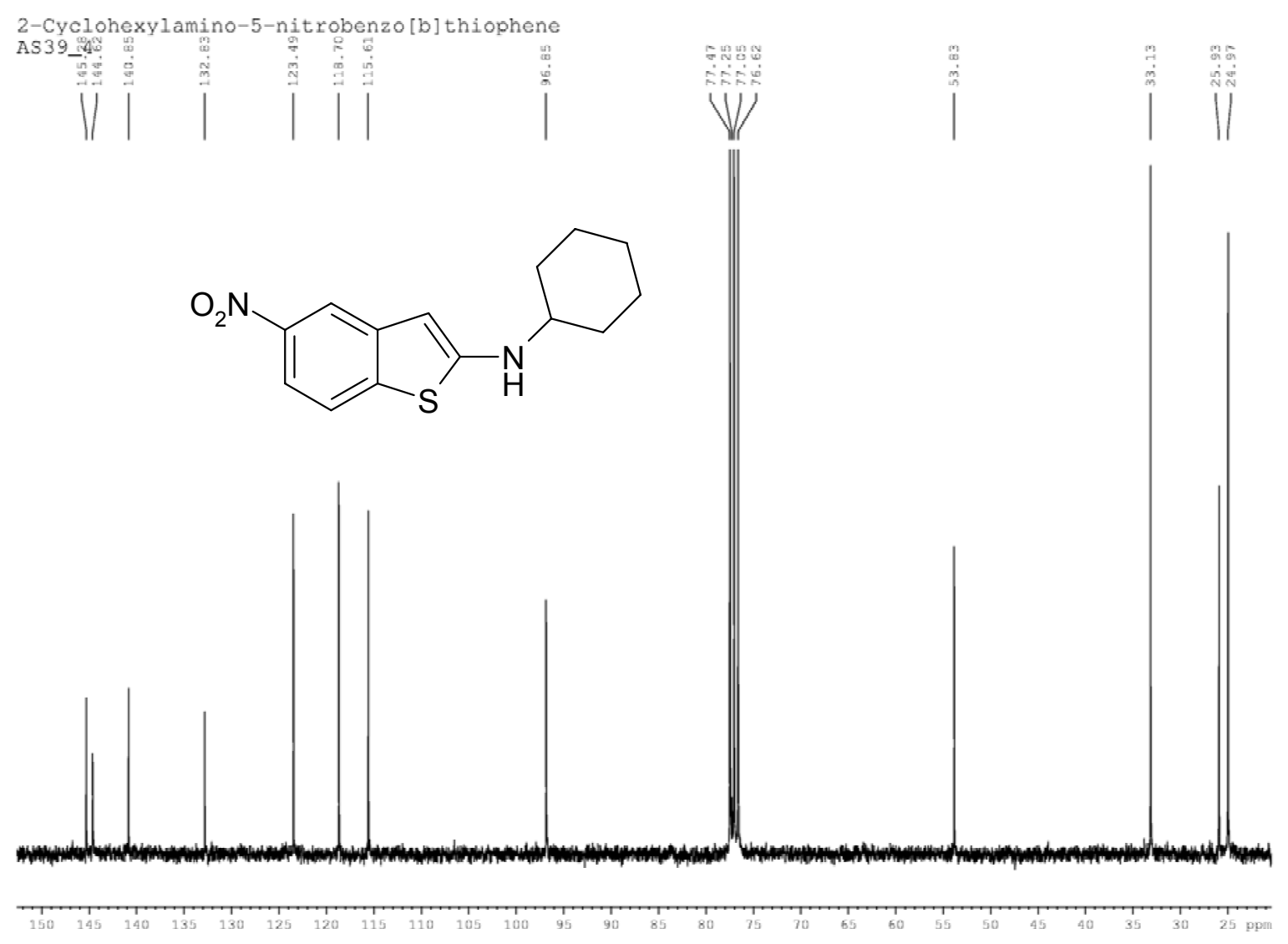


MS of cyclohexyl-(5-nitro-benzo[b]thiophen-2-yl)-amine (3g).

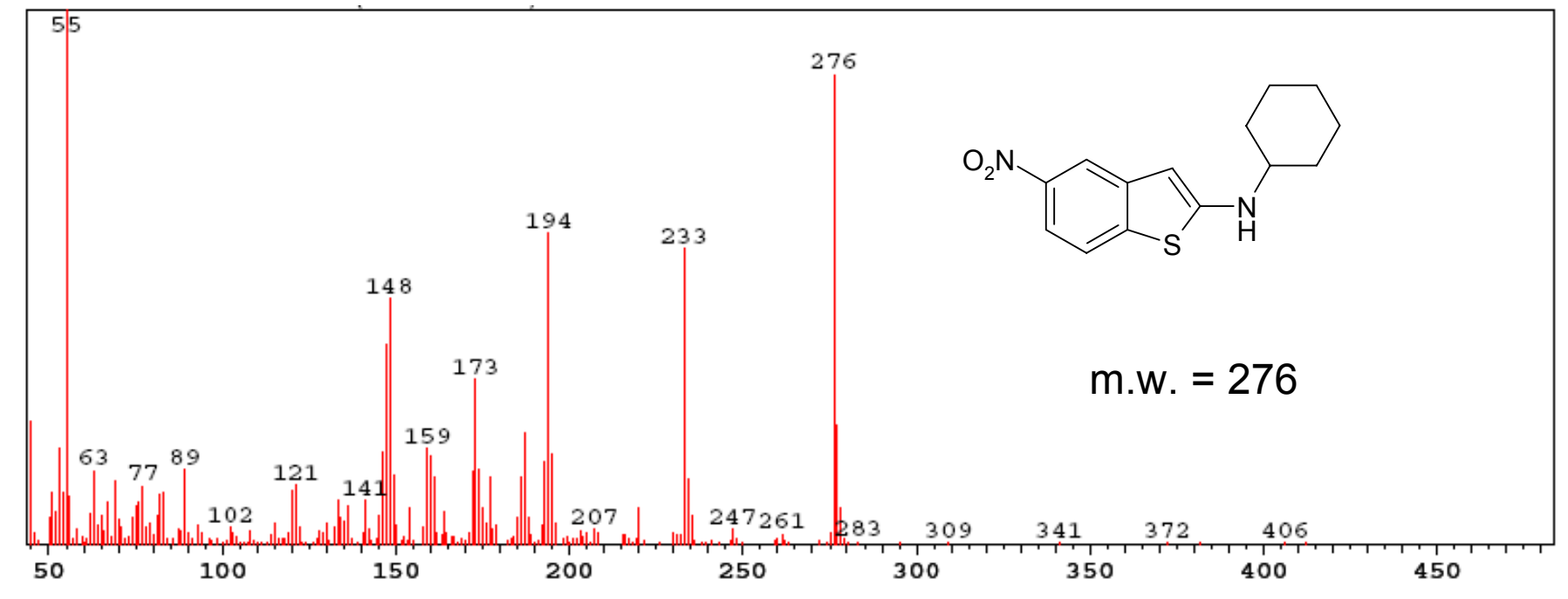




\section{${ }^{1} \mathrm{H}$-spectrum of dimethyl-(5-nitro-benzo[b]thiophen-2-yl)-amine (3h) in $\mathrm{CDCl}_{3}$}

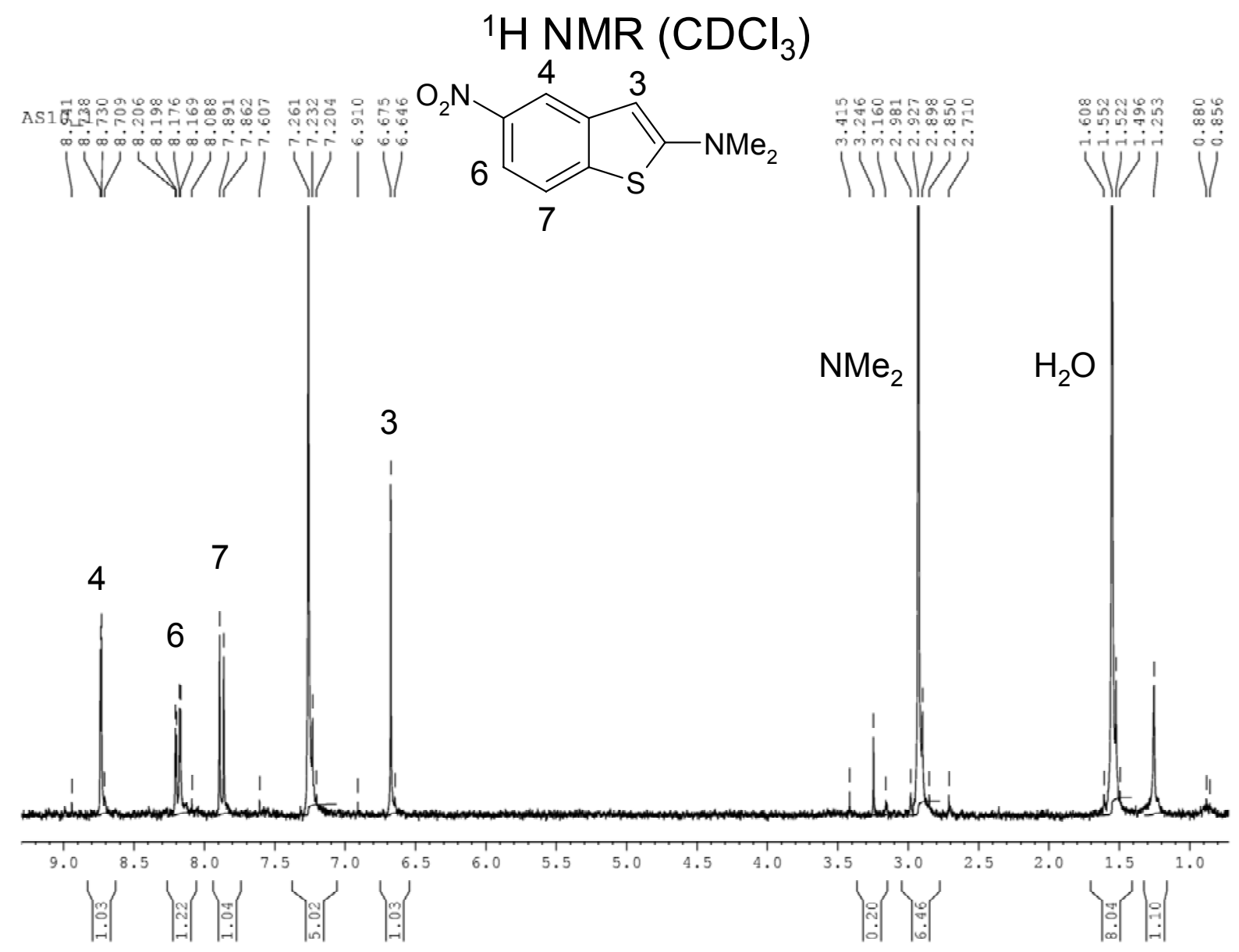


${ }^{13} \mathrm{C}$-spectrum of dimethyl-(5-nitro-benzo[b]thiophen-2-yl)-amine

(3h) in $\mathrm{CDCl}_{3}$.

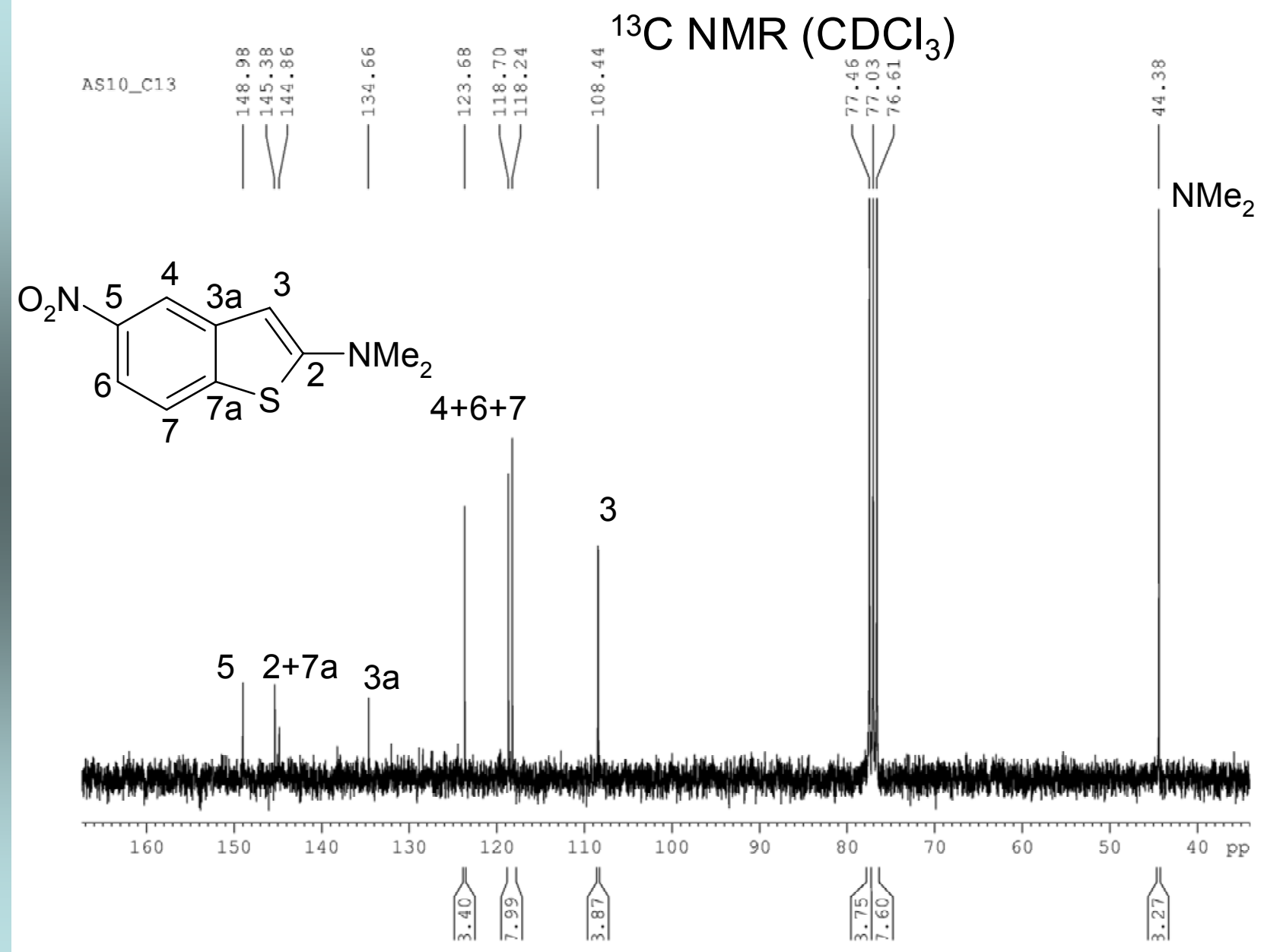


MS of dimethyl-(5-nitro-benzo[b]thiophen-2-yl)-amine (3h).

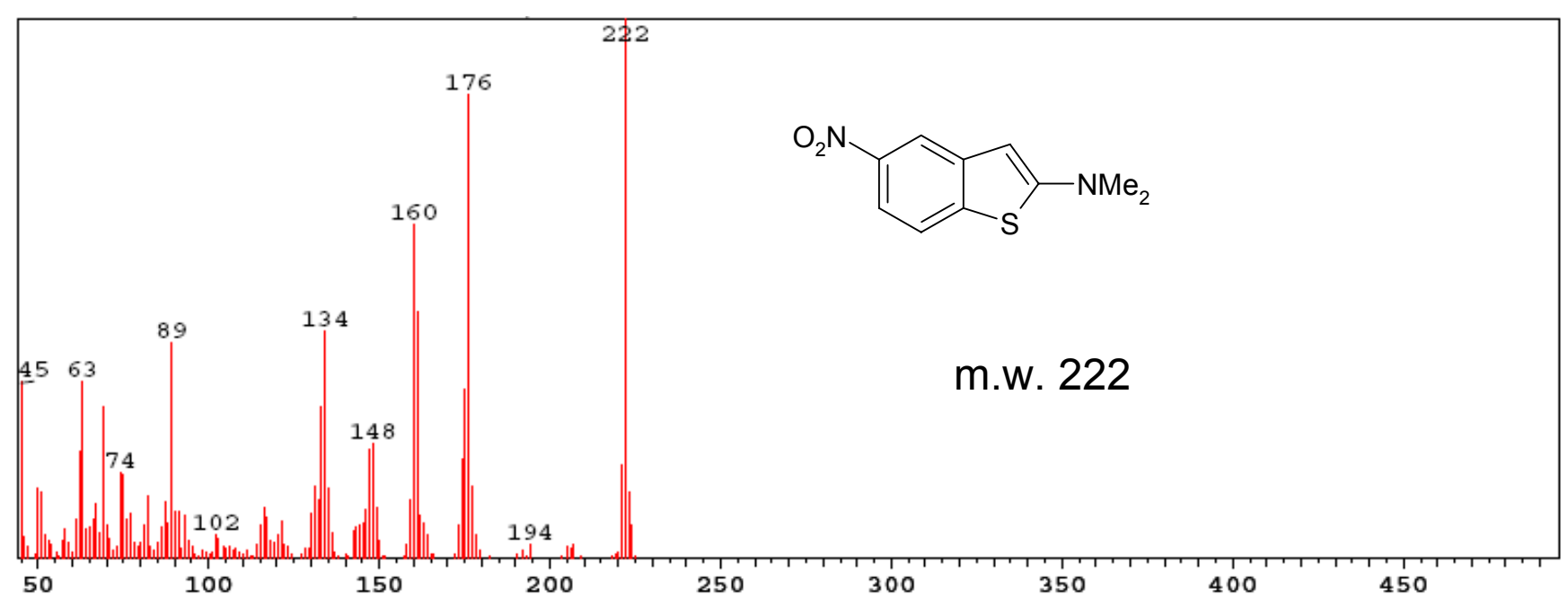


${ }^{1} \mathrm{H}$-spectrum of 1-(5-nitro-benzo[b]thiophen-2-yl)-pyrrolidine (3i) in $\mathrm{CDCl}_{3}$.

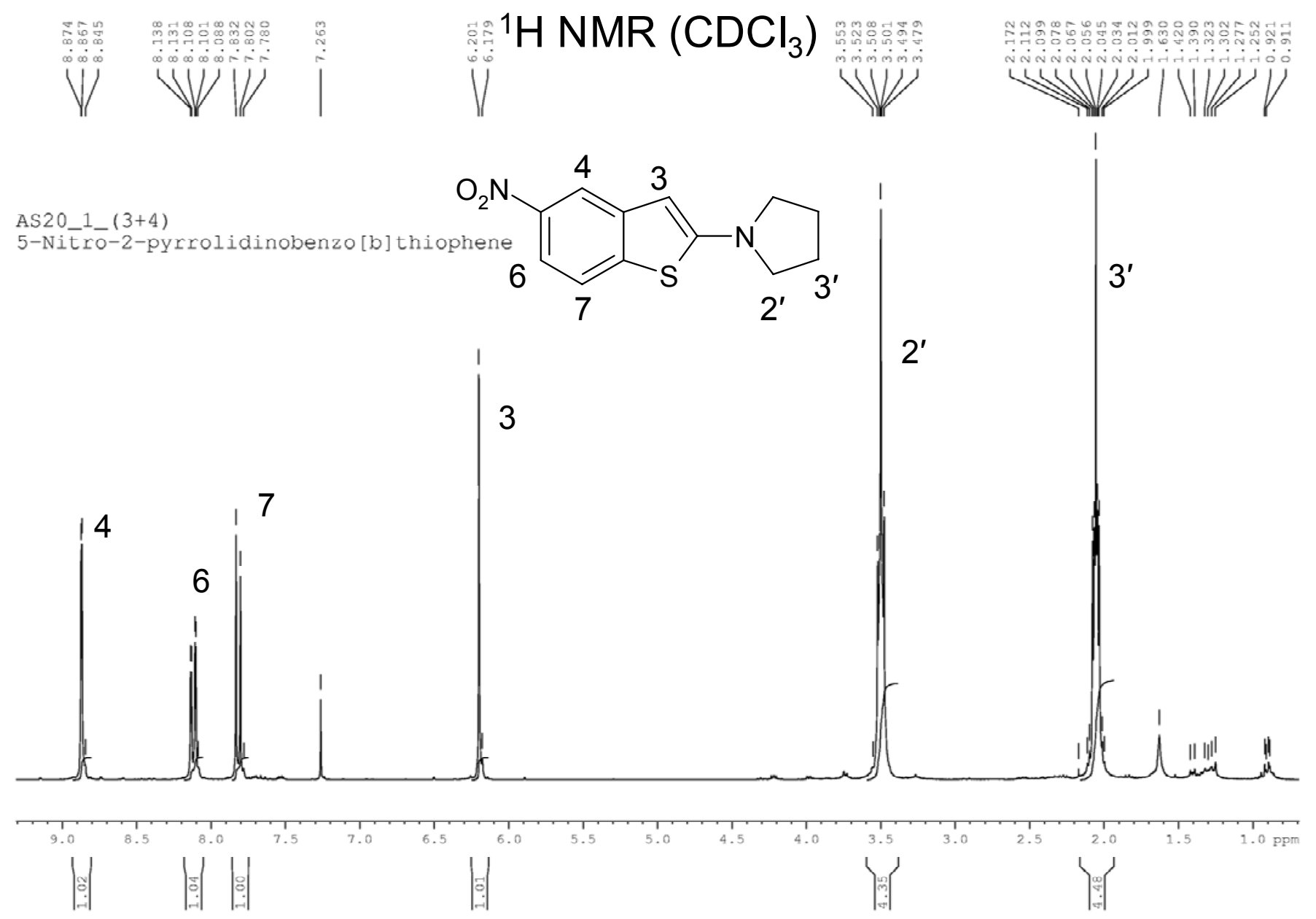


${ }^{13} \mathrm{C}$-spectrum of 1-(5-nitro-benzo[b]thiophen-2-yl)-pyrrolidine (3i) in $\mathrm{CDCl}_{3}$.

AS2U_1_ $(3+4)$

5-Nitro-2-pyrrolidinobenzo[b] thiophene

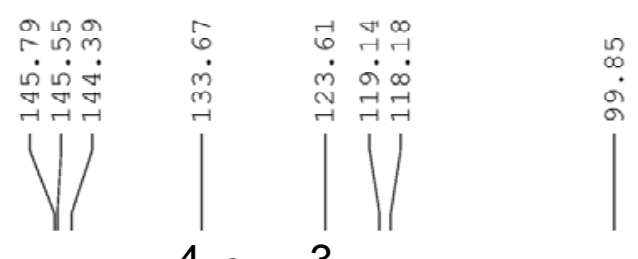

$\underbrace{\mathrm{O}_{2} \mathrm{~N}}_{7} \underbrace{5}_{\mathrm{s}^{\prime}} \mathrm{s}_{3^{\prime}}^{3}$

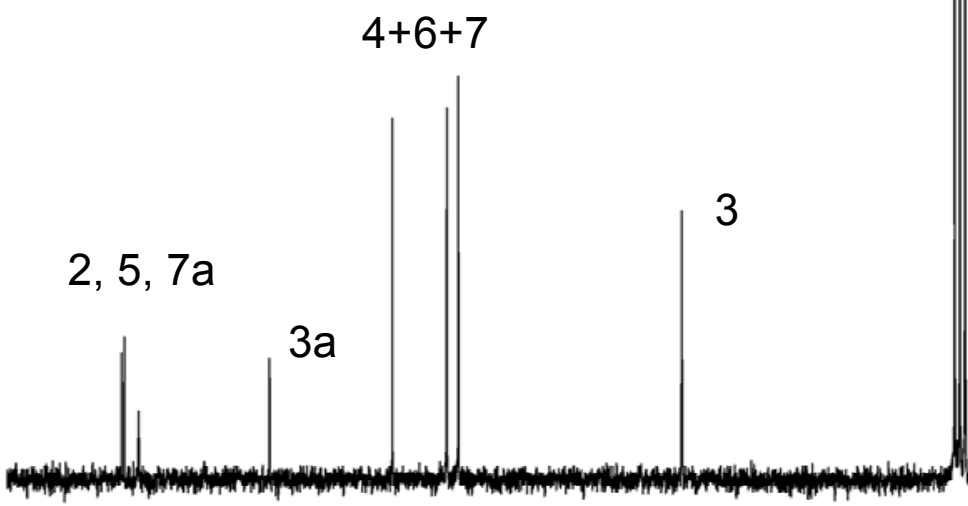

${ }^{13} \mathrm{C} \mathrm{NMR}\left(\mathrm{CDCl}_{3}\right)$
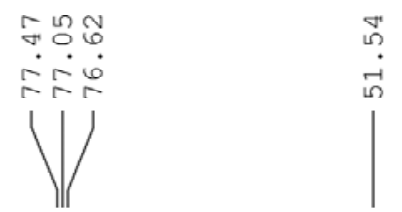

$\stackrel{\substack{N \\ \sim}}{\stackrel{\sim}{N}}$

$2^{\prime}$

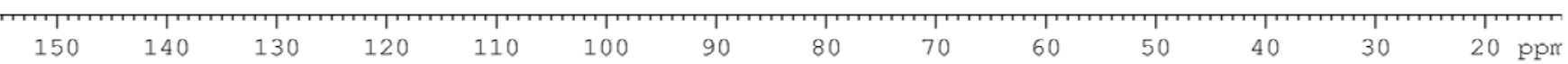




\section{MS of 1-(5-nitro-benzo[b]thiophen-2-yl)-pyrrolidine (3i).}

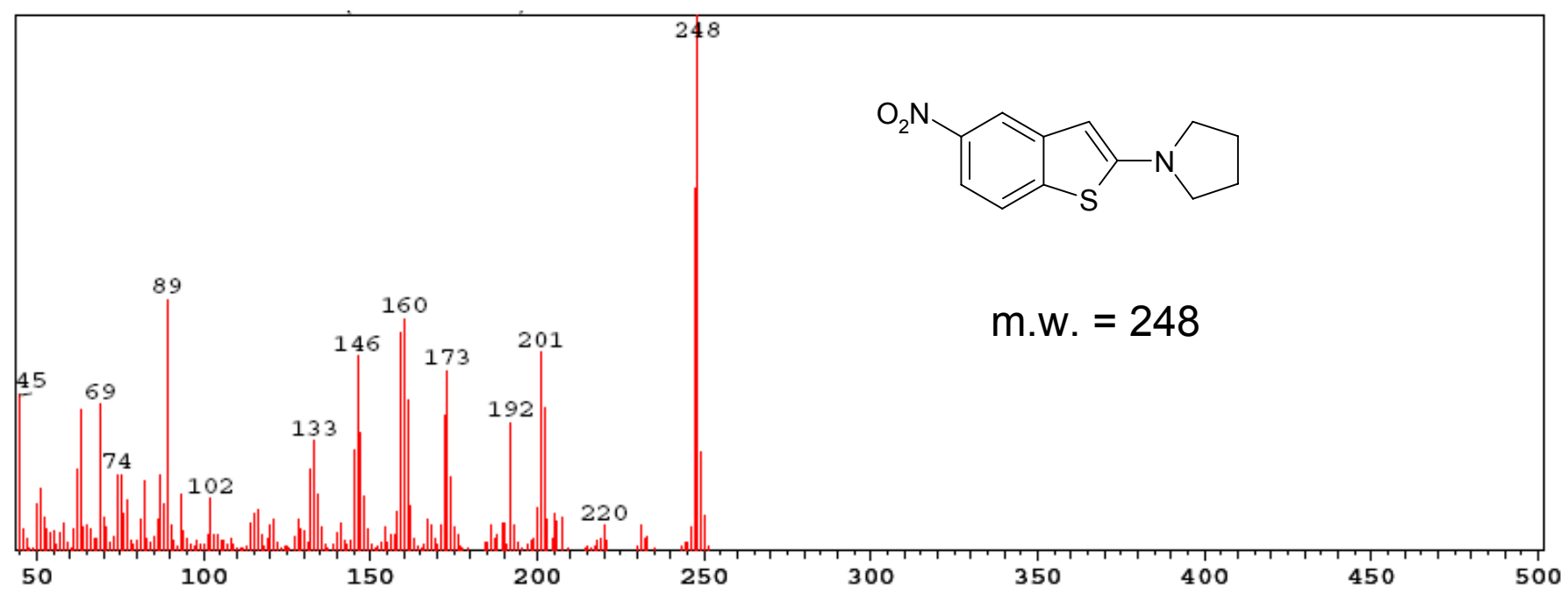


${ }^{1} \mathrm{H}$-spectrum of 1-(5-nitro-benzo[b]thiophen-2-yl)-piperidine (3j) in $\mathrm{CDCl}_{3}$.

\section{${ }^{1} \mathrm{H} \mathrm{NMR}\left(\mathrm{CDCl}_{3}\right)$}

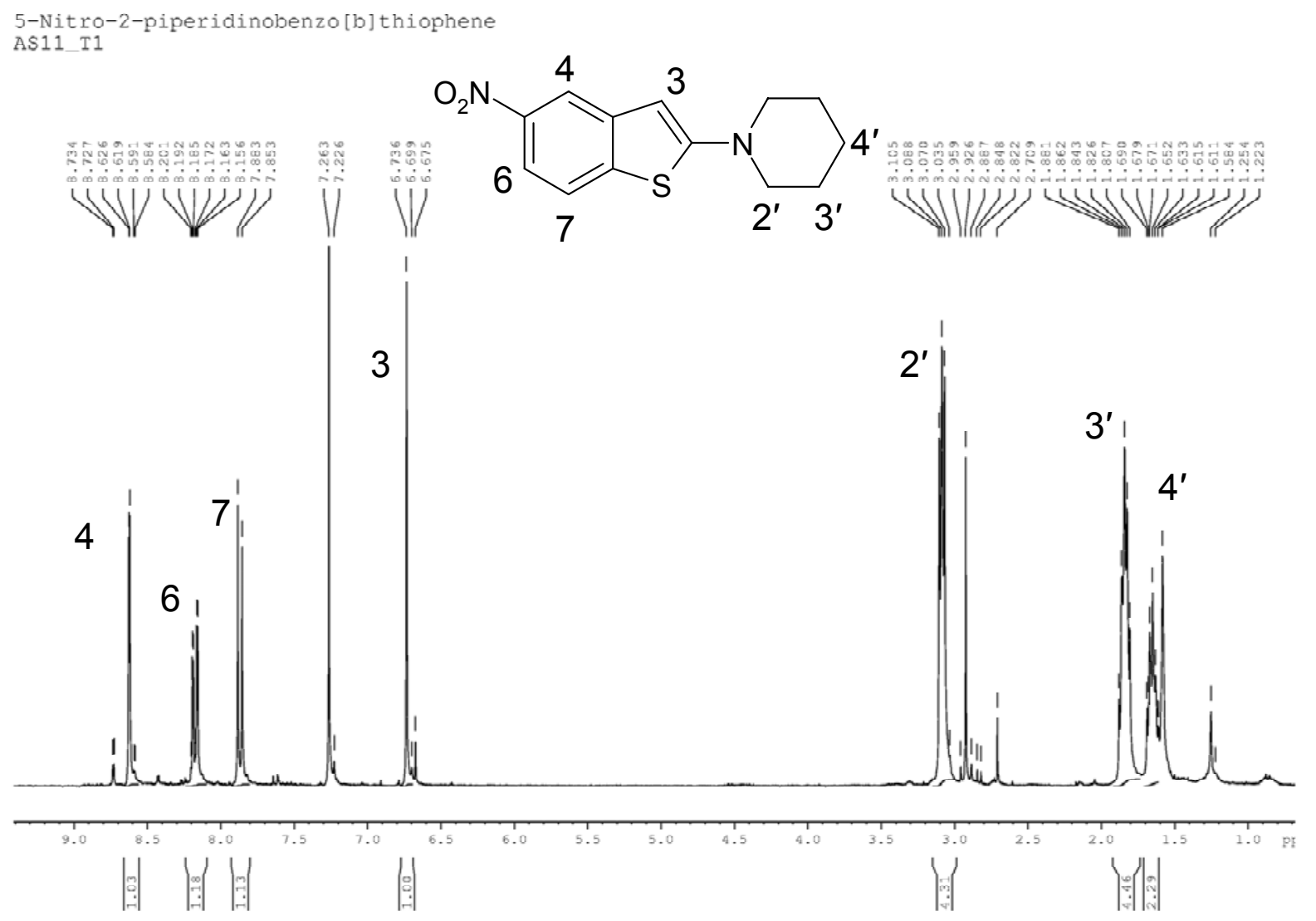


${ }^{13} \mathrm{C}$-spectrum of 1-(5-nitro-benzo[b]thiophen-2-yl)-piperidine (3j) in $\mathrm{CDCl}_{3}$.

\section{${ }^{13} \mathrm{C}$ NMR $\left(\mathrm{CDCl}_{3}\right)$}

5-Nitro-2-piperidinobenzo[b] thiophene
AS11 T1

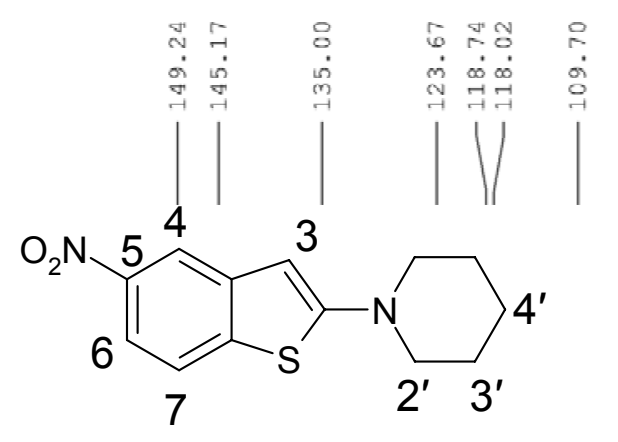

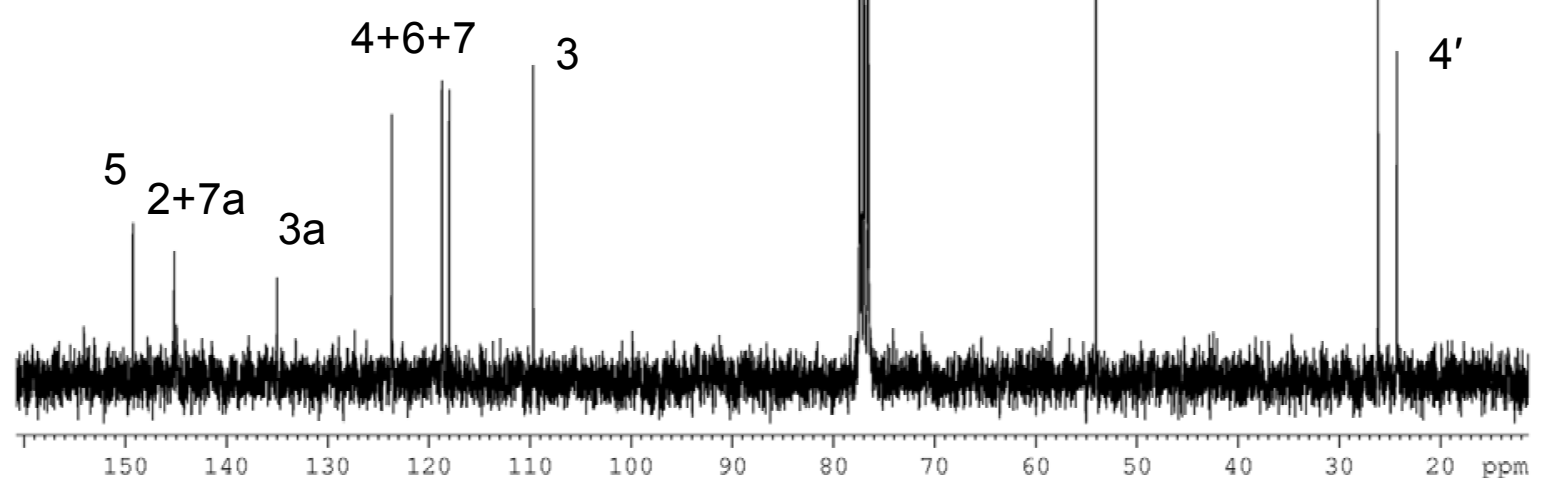


MS of 1-(5-nitro-benzo[b]thiophen-2-yl)-piperidine (3j).

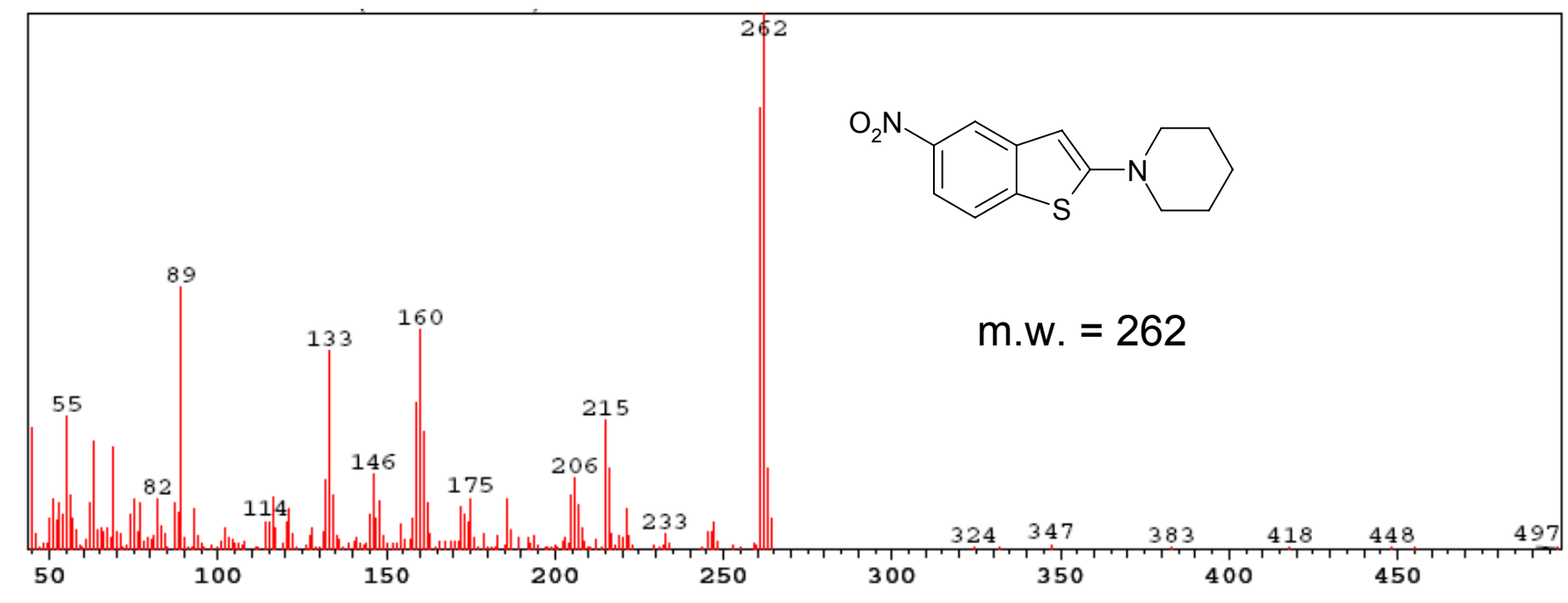


${ }^{1} \mathrm{H}$-spectrum of 4-(5-nitro-benzo[b]thiophen-2-yl)-morpholine (3k) in $\mathrm{CDCl}_{3}$.

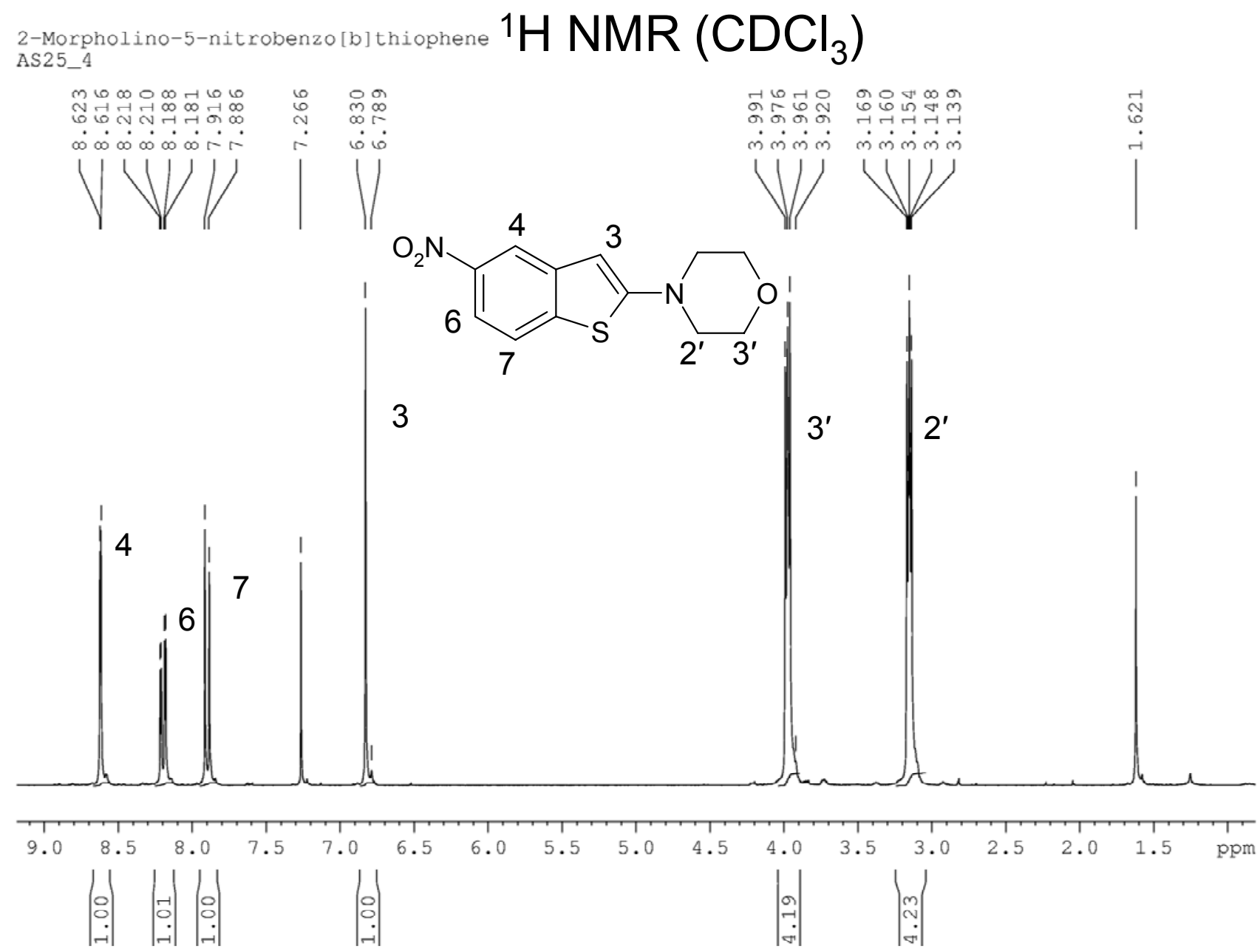




\section{${ }^{13} \mathrm{C}$-spectrum of 4-(5-nitro-benzo[b]thiophen-2-yl)-morpholine (3k) in $\mathrm{CDCl}_{3}$.}

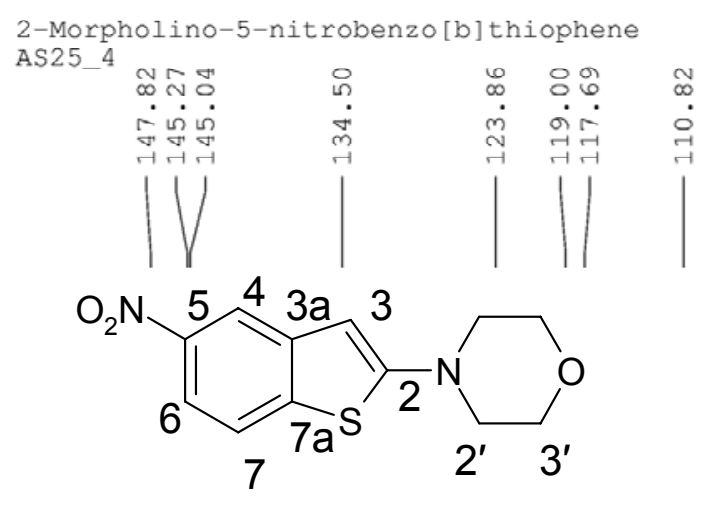

\section{${ }^{13} \mathrm{C}$ NMR $\left(\mathrm{CDCl}_{3}\right)$}
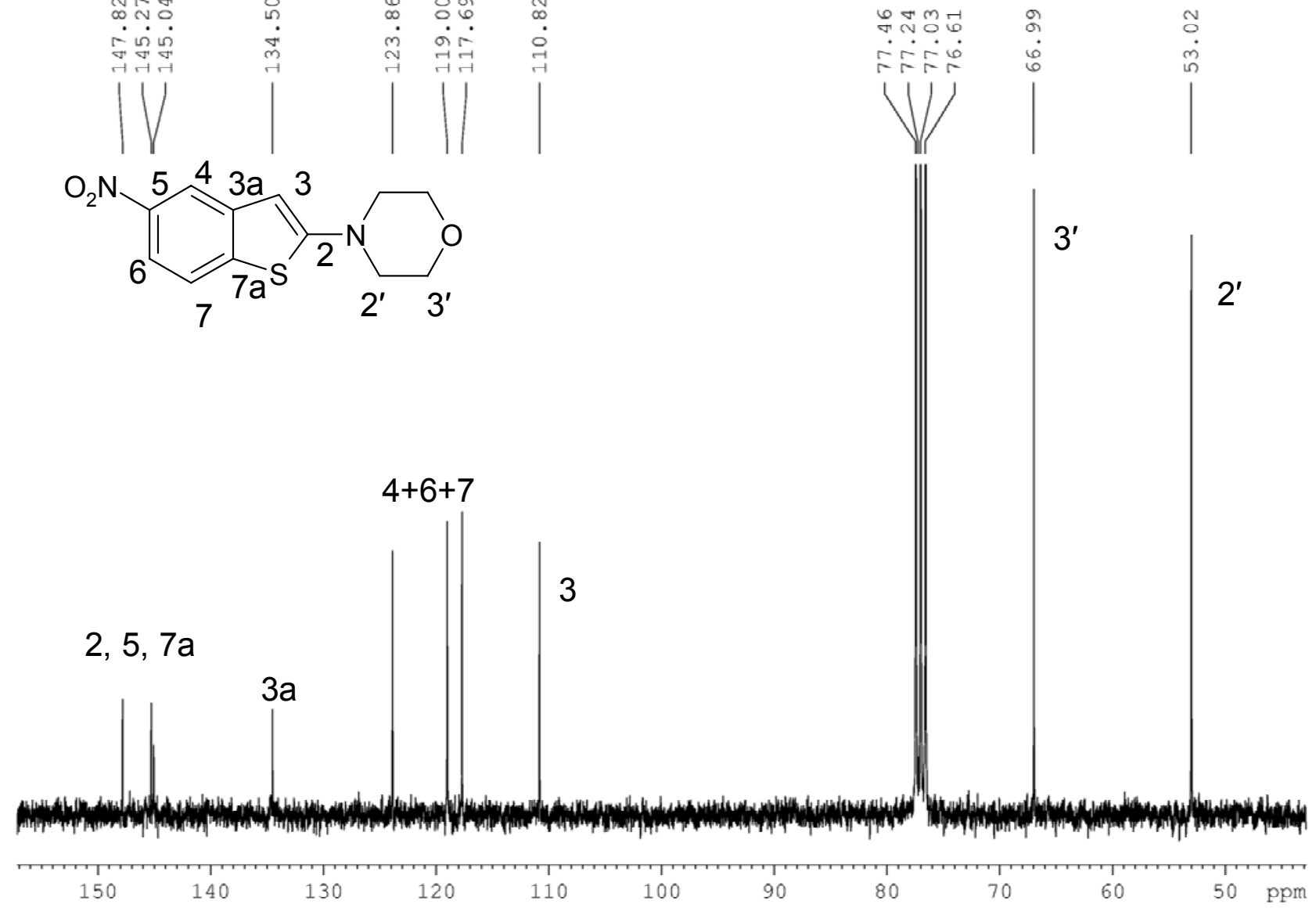
MS of 4-(5-nitro-benzo[b]thiophen-2-yl)-morpholine (3k).

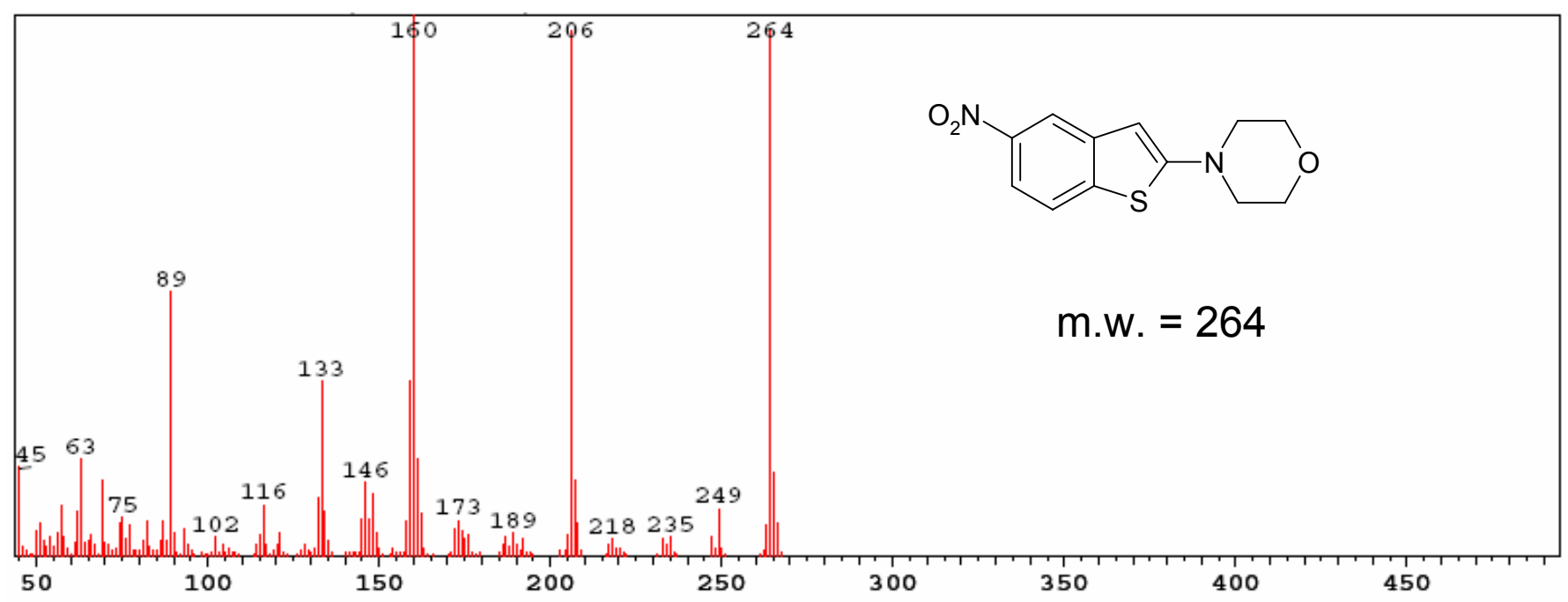




\section{${ }^{1} \mathrm{H}$-spectrum of 3-methyl-5-nitro-benzo[ $\left.d\right]$ isothiazole (4) in $\mathrm{CDCl}_{3}$.}

\section{${ }^{1} \mathrm{H} \mathrm{NMR}\left(\mathrm{CDCl}_{3}\right)$}

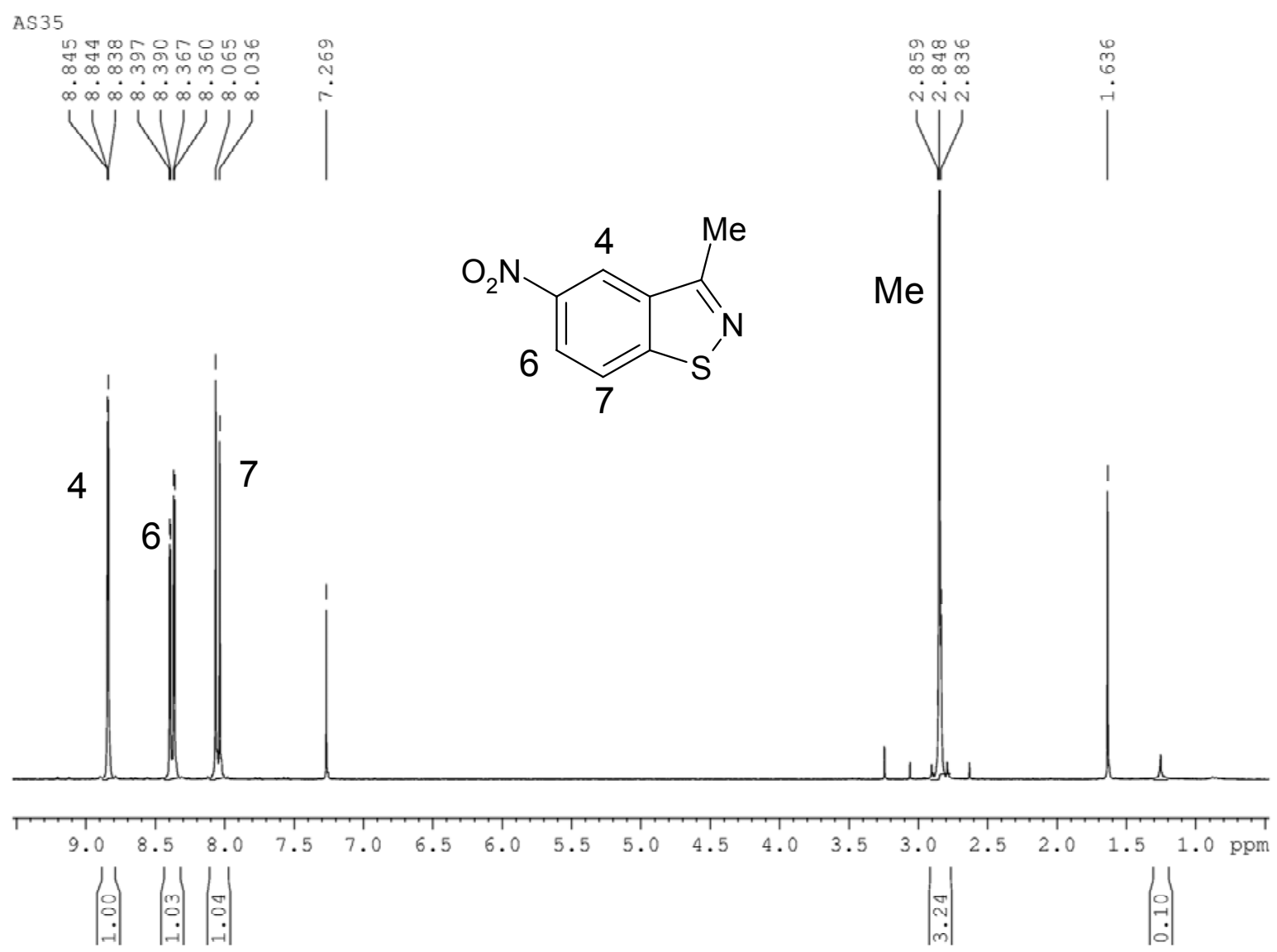




\section{${ }^{13} \mathrm{C}$-spectrum of 3-methyl-5-nitro-benzo[ $[d]$ isothiazole (4) in $\mathrm{CDCl}_{3}$.}

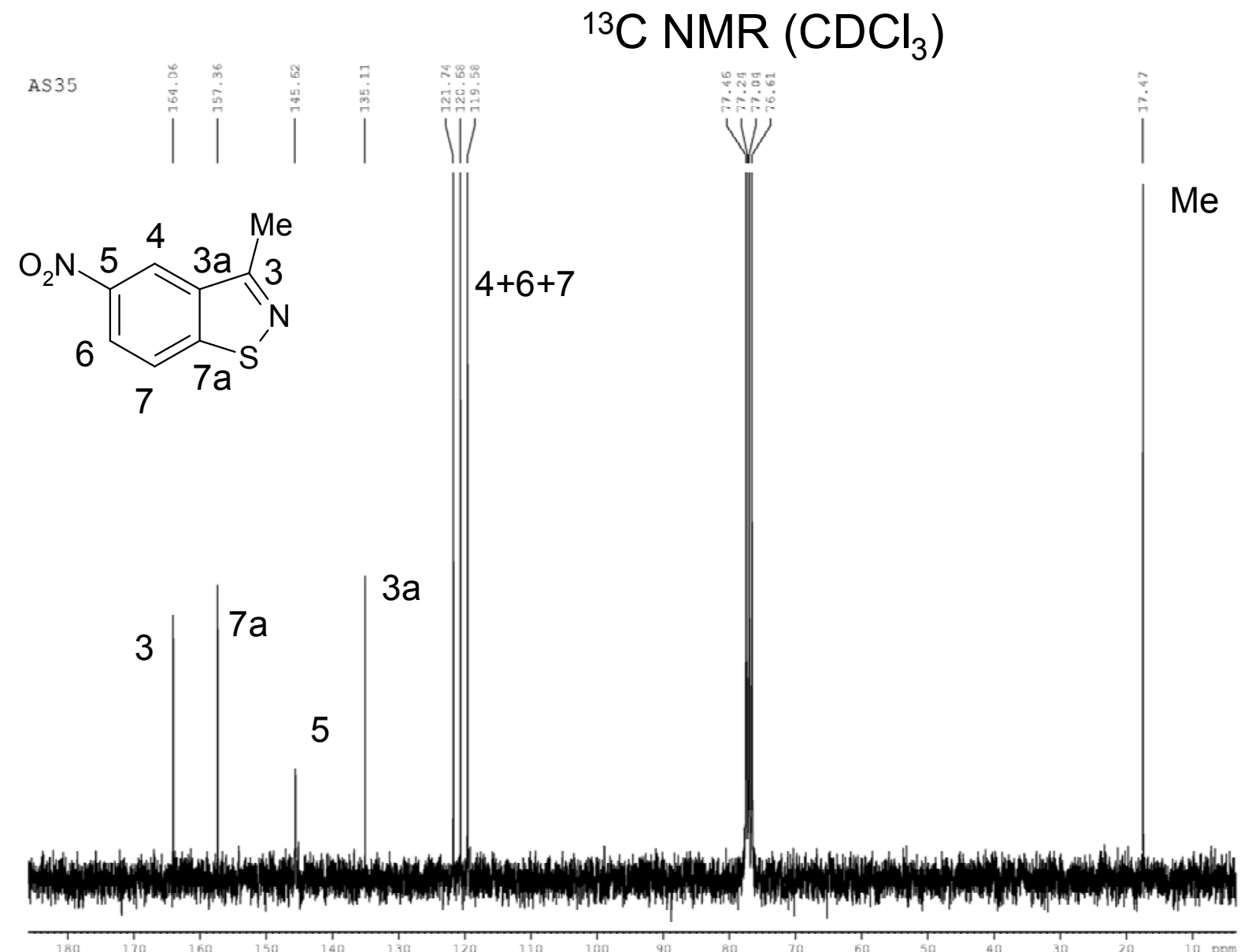


MS of 3-methyl-5-nitro-benzo[d]isothiazole (4).

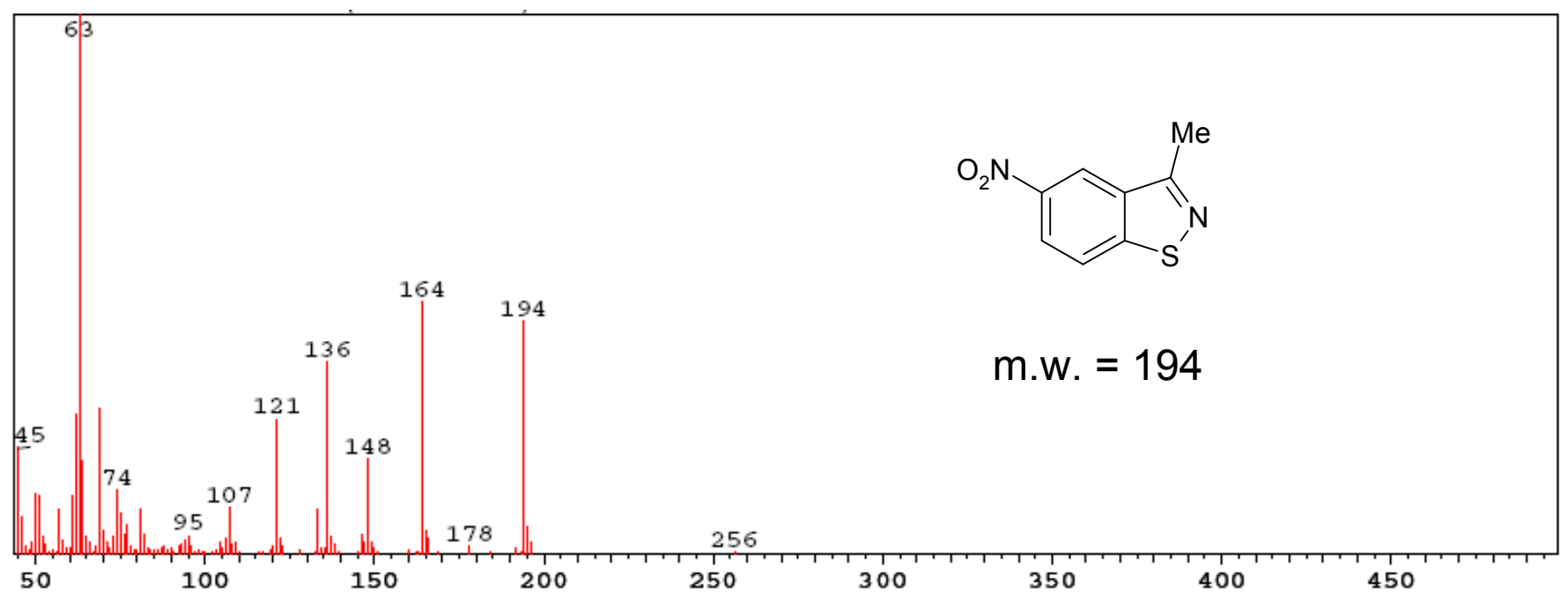




\section{General methods and materials.}

Reagents. All chemicals were used as purchased. Solvents for crystallization and chromatography were technical grade. When required, solvents were freshly distilled from appropriate drying agents before use.

General Methods. Analytical TLC was performed with silica gel $60 \mathrm{~F}_{254}$ plates. Melting points are uncorrected. Mass spectra were obtained on a triple quadrupole mass spectrometer by electron ionization (EI) at $70 \mathrm{eV}$. High-resolution mass spectra were recorded on a double focusing magnetic sector mass

spectrometer using using EI at $70 \mathrm{eV} .{ }^{1} \mathrm{H}$ and ${ }^{13} \mathrm{C}$ NMR spectra were recorded at 300 and $75 \mathrm{MHz}$ respectively, in $\mathrm{CDCl}_{3}$ using TMS ( $\left.\delta=0.0 \mathrm{ppm}\right)$ or the signal of residual solvent protons as an internal standard.

GC-MS analyses were carried out using a gas chromatograph with a series mass selective detector (EI, $70 \mathrm{eV}$ ), using a capillary column of $25 \mathrm{~m}$ length and $0.25 \mathrm{~mm} \mathrm{I.D.} \mathrm{An} \mathrm{initial} \mathrm{temperature} \mathrm{of} 70{ }^{\circ} \mathrm{C}$ was maintained for $3 \mathrm{~min}$ and then a heating rate of $20^{\circ} \mathrm{C} / \mathrm{min}$ was applied until the final temperature of 270 ${ }^{\circ} \mathrm{C}$ was reached. 